\author{
Elsevier Editorial System(tm) for Materials and Design \\ Manuscript Draft
}

Manuscript Number: JMAD-D-11-00901R1

Title: Characterization of Magnesium Spot Welds under Tensile and Cyclic Loadings

Article Type: Original Article

Keywords: Magnesium alloys (A); spot weld (D); characterization (G)

Corresponding Author: Mr. Seyed Behzad Behravesh,

Corresponding Author's Institution: University of Waterloo

First Author: Seyed Behzad Behravesh

Order of Authors: Seyed Behzad Behravesh; Hamid Jahed; Steve Lambert

Abstract: Resistance spot welds of a magnesium alloy were characterized in terms of microstructure, hardness and monotonic and cyclic properties. Microstructural features in base metal and different zones in the weld region were discussed and the mechanical behavior of spot welds in tensile-shear configuration was studied. Effects of welding parameters were investigated on the micro- and macroscale characteristics of magnesium spot welds. To this end, five sets of spot weld specimens were prepared, utilizing different welding parameters. The effect of cyclic loading was studied on microstructure and hardness of the base metal and the weld region, and it was shown that microstructural features do not change remarkably under cyclic loading. Fatigue crack initiation and propagation behavior was discussed for different specimen sets under both low and high cyclic loads. Fatigue cracks under high cyclic loading initiated close to the nugget edge, and decreasing the cyclic load nucleated the cracks farther from the nugget. 


\title{
Characterization of Magnesium Spot Welds under Tensile and Cyclic Loadings
}

Seyed Behzad Behravesh*, Hamid Jahed, Steve Lambert

Mechanical and Mechatronics Engineering Department, University of Waterloo, Waterloo, Ontario, N2L3G1, Canada

*Corresponding Author: Tel. +1-519-721-1073 ; Fax: +1-519-885-5862 ; Email:

sbbehrav@engmail.uwaterloo.ca

\begin{abstract}
Resistance spot welds of a magnesium alloy were characterized in terms of microstructure, hardness and monotonic and cyclic properties. Microstructural features in base metal and different zones in the weld region were discussed and the mechanical behavior of spot welds in tensile-shear configuration was studied. Effects of welding parameters were investigated on the micro- and macro-scale characteristics of magnesium spot welds. To this end, five sets of spot weld specimens were prepared, utilizing different welding parameters. The effect of cyclic loading was studied on microstructure and hardness of the base metal and the weld region, and it was shown that microstructural features do not change remarkably under cyclic loading. Fatigue crack initiation and propagation behavior was discussed for different specimen sets under both low and high cyclic loads. Fatigue cracks under high cyclic loading initiated close to the nugget edge, and decreasing the cyclic load nucleated the cracks farther from the nugget.
\end{abstract}

Keywords: Magnesium alloys (A); spot weld (D); characterization (G) 


\section{Introduction}

To comply with ever restricting environmental laws and improve performance, automotive manufacturers need to decrease the weight of automobiles. Magnesium, as the lightest commercial engineering metal, has recently attracted more attention in the automobile industry. The trend in the average magnesium usage per car has been rapidly increasing from $3 \mathrm{~kg}$ in 2005 to $20 \mathrm{~kg}$ in 2010, and is projected to reach 50 $\mathrm{kg}$ in 2015 [1]. While magnesium has wide application in automotive components such as casings, housings, and trim parts; to achieve its role as a major material in automotive manufacturing, its application to load bearing components is necessary. It is therefore essential to examine the merits of components made of magnesium under both static and cyclic loads.

From the joining perspective, applicability of welding techniques for automotive body parts has been studied mainly using steel and aluminum [2-7]. With the new interest in magnesium, the feasibility and performance of joining processes such as tungsten inert gas (TIG), laser welding, hybrid laser-TIG welding, friction stir, and resistance spot welding have been investigated on magnesium alloys in recent years [8-13]. Nevertheless, resistance spot welding (RSW), is still the predominant joining technique in automobile body assembly lines [14], as it allows quick and cost effective fabrication of complicated assemblies.

On the other hand, service reports of automobiles show that a major proportion of structural durability issues are related to spot welds [15], which is due to the fact that spot welds act as stress concentration sites, and are therefore more susceptible to fatigue failure. As a result, studying the fatigue behavior of spot welds is of great significance.

The majority of studies in fatigue of RSW with automobile applications have been on steel and aluminum alloys [16-19]. These studies can be categorized into four major groups: fatigue modeling, comparative studies (RSW vs. other joining processes), process optimization, and characterization. 
Many researchers have focused on developing models to estimate the fatigue life of spot welds. The main approaches in these models include: structural stress [20-23], local stress/strain [21, 24-27], stress intensity factor [24, 28-30], and crack growth [31-33].

A number of studies with the aim of comparing the fatigue performance of RSW with other welding processes have been done for similar and dissimilar materials. Wang and Ewing [34] compared the fatigue resistance of laser weld and spot welds of steel sheets with "equivalent weld volume" as the comparison base. Uematsu and Tokaji [35] investigated the strength and failure modes of RSW and friction stir spot welds (FSSW) for an aluminum alloy under static and cyclic loading. Long and Khanna [36] compared static and fatigue strength of spot weld with spot weld bond specimens of high strength steels in tensile-shear and coach-peel configurations. Sun, et al. [37] studied spot weldability of aluminum to steel and compared the monotonic and cyclic preformance of spot weld with self piercing rivets (SPR) of these dissimilar materials.

Some studies, on the other hand, have focused on modifying the spot weld joints for improving fatigue strength. Overbeeke and Draisma [38] heat-treated spot weld specimens to release welding residual stresses and to enhance fatigue life. Post weld cold-working and in-process forging force are two techniques for inducing beneficial compressive residual stress which delay the crack initiation that have been proposed. Kim, et al. [39-41], and Spitsen, et al. [42] studied the effect of post-weld cold working on tensile and fatigue strength of aluminum and steel spot welds and optimized the cold working process parameters. Chang, et al. [43] applied in-process forging force as a part of the welding process to induce compressive residual stress in the heat affected zone.

Characterizing fatigue behavior of spot welds has attracted various researchers' attention. Some researchers investigated the effects of sheet thickness, coupon width, nugget diameter, mean load, and base metal strength on fatigue strength. Mean stress [44] and base metal strength $[14,45]$ have been reported to have negligible effect on the fatigue life. On the other hand, geometric parameters such as sheet thickness [45-46], coupon width [45], and spot weld diameter [44-45, 47-48] have been identified as 
the most significant factors on fatigue strength of spot welds. Davidson and Imhof [30] have reviewed the effects of these parameters on fatigue strength in low and high cycle regimes. Nugget size effect on fatigue resistance of steel and aluminum spot welds as reported by Pollard [47] and Gean, et al. [48] is noticeable for low cycle but not in the high cycle regime. The effects of cyclic loading on hardness in the base metal and spot weld area have been investigated as part of the fatigue characterization of spot welds. Long and Khanna [49] reported that high cyclic loading caused noticeable softening in the weld area of high strength, low alloy (HSLA) steel spot welds, while the effect of low cyclic loading was negligible on hardness in the base metal and weld area. A number of studies investigated the effects of cyclic loading condition on crack initiation and propagation. Radaj [24] suggested that fatigue cracks in tensile-shear steel spot welds initiate from the nugget edge under small cyclic loads and away from the nugget edge under medium and large cyclic loads; in either case, cracks propagated through the sheet thickness. Long and Khanna [49] reported that in tensile-shear spot welds of HSLA steels, cracks started in the heat affected zone under high load conditions, but started in the base metal adjacent to the heat affected zone under low loads.

To the best of the authors' knowledge there has been no report on the fatigue of magnesium resistance spot welds.

The present research was aimed at characterizing the microstructural and mechanical behavior of RSWs in Mg-alloys under uniaxial and cyclic loads. Microstructure and hardness in base metal and in different regions of the weld area were studied. Strengths and modes of failure under monotonic and cyclic loadings were studied on spot weld specimens in tensile-shear configurations, and compared with those in steel and aluminum from mechanistic point of view. The effects of welding parameters on these characteristics were investigated by studying five sets of specimens prepared using different process parameters. The effects of cyclic loading were then studied on microstructural features in the weld regions. Fatigue crack initiation and propagation behavior are discussed under both low and high cyclic loading. 


\section{Experimental Procedure}

\subsection{Material and Specimens}

The specimens in this study were made from AZ31B-H24 magnesium alloy in the form of sheet with 2 $\mathrm{mm}$ thickness. These sheets were produced by hot rolling followed by annealing to half of the initial hardness. The chemical composition and mechanical properties are shown in Table 1 and Table 2, respectively [50].

Spot weld specimens were prepared in the tensile-shear configuration with the geometry shown in Figure 1. Coupons were cut along the sheet rolling direction and the surfaces were cleaned with chromic acid (2.5gr CrO3+100ml $\mathrm{H} 2 \mathrm{O}$ ) before welding, to obtain spot welds with less porosity and expulsion [51].

Two shims were used at the ends to fill out the coupons offset to prevent additional coupon bending during testing.

Five sets of specimens were prepared with different nugget diameters using different welding parameters, as listed in Table 3. Nugget sizes were measured after monotonic testing as the average diameters of the bonding area, along and perpendicular to the loading directions.

Some of the specimens from sets A, C, and E were used to prepare metallographic samples for studying the effect of welding parameters and cyclic loading on the microstructure and hardness in the base metal and the weld region. These specimens were sectioned slightly offset from the nugget centerline, along the loading direction. The samples were then mounted, ground, and polished to the nugget centerline and etched with a solution of $4.2 \mathrm{gr}$ picric acid, $10 \mathrm{ml}$ acetic acid, $70 \mathrm{ml}$ ethanol, and $10 \mathrm{ml}$ water.

\subsection{Testing Procedures}

All tests were performed at standard laboratory conditions. Monotonic testing was performed on the tensile-shear specimens in displacement-controlled mode, with the cross-head displacement rate of 1 $\mathrm{mm} / \mathrm{min}$ at room temperature. The failure mode and the load and displacement histories were recorded in 
each test. These tests were done on the five specimen sets listed in Table 3 to investigate the effect of nugget size on the ultimate tensile-shear load.

Fatigue tests were conducted under load-control with a load ratio $\mathrm{R}=\mathrm{L}_{\min } / \mathrm{L}_{\max }=0.2$, where $\mathrm{L}_{\min }$ and $\mathrm{L}_{\max }$ are minimum and maximum loads, respectively. A sinusoidal waveform was applied and the loading frequency was between 2 and $30 \mathrm{~Hz}$ depending on the load level. Final separation of coupons was considered as failure and tests stopped after 10 million cycles were considered run-outs. The load and cross head displacement histories, number of cycles, as well as the failure modes were recorded in all fatigue tests. Three sets of specimens (A, C, and E) were chosen for fatigue testing to study the effect of nugget size on cyclic behavior of $\mathrm{Mg}$ spot welds.

The micro-indentation hardness of the welds were measured on the cross-sections using a Vickers Microhardness apparatus. Testing was performed with a $100 \mathrm{gr}$ indentation load and with a holding time of 15 seconds.

\section{Results and Discussion}

As mentioned in section 2.1, five sets of specimens were investigated in this study, named A to E. Nevertheless, in the next few sections, i.e. sections 3.1 to 3.4 , the spot weld itself is studied. The results and discussion in these parts correspond to specimens from set $\mathrm{C}$, with parameters listed in Table 3. Section 3.5 deals with the effect of welding parameters on spot weld characteristics.

\subsection{Microstructure}

Microstructure in AZ31B magnesium spot welds consists of base metal (BM), heat affected zone (HAZ), partially melted zone (PMZ), and fusion zone (FZ). Figure 2, showing a quarter of a spot weld, illustrating these regions.

Figure 3 shows the microstructure of the BM in rolling and transverse directions (RD and TD). It can be seen that grains were equiaxed with approximately the same average grain size of $5 \mu \mathrm{m}$ in RD and TD. 
The reason why grains were not elongated in the rolling direction was recrystallization during the annealing process after rolling into AZ31B-H24 sheet.

Heat affected zone is the region where the temperature is high enough to change the microstructure, i.e. recrystallization, but not for melting. Figure 4(a) displays the microstructure of the HAZ with a grain size gradient, i.e. 10 to $6 \mu \mathrm{m}$, decreasing toward the BM boundary. The reason is that the regions in the HAZ close to the BM had a lower annealing temperature and time than regions neighboring the PMZ. Also, considering liquation does not occur in the HAZ, even in grain boundaries with a lower melting point than grains, intermetallic particles were not expected to form in this region due to the higher cooling rate. Figure 4(b) shows an SEM image from the HAZ without any indication of intermetallics. Another microstructural feature is that the twin band density is remarkably higher in the HAZ than in the BM. The partially melted zone is the region surrounding the FZ in which liquation may happen locally during welding. The microstructure in the PMZ is shown in Figure 5. The peak temperature in PMZ of AZ31 is between solidus and liquidus temperatures, and therefore grain boundaries due to higher aluminum content and lower melting point may liquate. During solidification, because of high cooling rate, the aluminum content does not have enough time to make a homogeneous solid solution in the $\alpha$-matrix. Therefore intermetallics $\left(\mathrm{Al}_{12} \mathrm{Mg}_{17}\right)$ are formed as the second phase in the grain boundaries of PMZ, as can be seen in Figure 5(b).

The fusion zone is the region which experiences complete liquation during welding. Figure 6 displays representative microstructures in the fusion zone. Porosity, as shown in Figure 6(a), existed in the FZ and increasing the welding current raised the chance of developing, and the size of porosity. Porosity may weaken spot welds under loading conditions that cause failure in the nugget, i.e. monotonic and high cyclic loading, as will be discussed in sections 3.3 and 3.4. According to Figure 6(b), the FZ in AZ31B spot welds had an equiaxed dendritic structure.

Intermetallic particles during solidification were pushed away from dendrites and gathered in interdendritic regions, which are shown as light-etching regions in the SEM image of Figure 6(b). 


\subsection{Hardness}

Figure 7(a) shows a schematic of the spot weld cross section with small dots representing the indentation path, and the graph in Figure 7(b) displays the hardness profile obtained from micro-indentation Vickers hardness testing.

The profile in this figure shows that the hardness in AZ31B-H24 magnesium spot welds in the BM and the weld area are almost the same. With dissimilar microstructures in the different zones, two phenomena are acting to counteract one another with respect to hardness. Increasing the grain/dendrite size from the $\mathrm{BM}$ to the FZ tends to decrease the hardness. On the other hand, intermetallics present in the PMZ and FZ and twin bands in the HAZ increase the hardness. The hardness profile suggests that these effects have counteracted one other, resulting in a uniform hardness distribution.

This observation is contrary to what has been reported for friction stir welds (FSW) and laser beam welds (LBW) of AZ31B-H24, both of which result in lower hardness in the weld region than the BM [52-53]. Therefore, RSW has superior performance compared with FSW and LBW from the viewpoint of strength in the weld region.

On the other hand, RSW of steel and aluminum results in a non-uniform hardness distribution. Hardness in the FZ of steel spot welds is higher than the BM [54], while it's lower in the FZ of aluminum spot welds than the BM [55]. The uniform hardness distribution in $\mathrm{Mg}$ spot welds can be considered a minor advantage compared with aluminum spot welds, under loading which causes nugget failure.

\subsection{Quasi-static behavior}

Quasi-static testing was performed to evaluate the load carrying capacity of spot welds in the tensile-shear configuration under static loading. Five specimens were tested and the average ultimate tensile-shear load (UTSL) turned out to be $6.67 \mathrm{kN}$. 
Quasi-static loading yielded two failure modes. "Interfacial failure" was the dominant mode of rupture; 4 out of 5 specimens tested failed in this mode. As shown in Figure 8(a), failure occurred in this mode through the nugget at the interface. The other mode of failure was "partially interfacial", as illustrated in Figure 8(b), in which the failure started in the interfacial mode and continued through the coupon thickness and left a button on one coupon and a hole on the other side.

The same failure modes have been observed in aluminum spot welds $[48,56]$, while partially interfacial and "button pullout" are the most common failure modes in well-prepared steel spot welds under monotonic tensile-shear loading [48, 57-58]. Button pullout is a failure mode in which one coupon tears around the HAZ, resulting in a plug on one coupon and a hole on the other coupon, but unlike partially interfacial failure there is no nugget shear-off in this mode. One of the reasons why magnesium and aluminum spot welds fail through the weld is that hardness and therefore strength in the FZ is comparable or less than the BM. Steel spot welds, however, due to significantly higher hardness and strength in the FZ, fail primarily in partially interfacial mode, without failure in the weld.

\subsection{Cyclic behavior}

Fatigue tests were performed to study the strength of spot welds in the tensile-shear configuration under cyclic loading. The fatigue life experimental data and the corresponding Load-life (L-N) curve obtained from the best bi-linear regression fit using a log-log scale are shown in Figure 9.

The spot weld specimens failed in three different failure modes under cyclic loading: interfacial, partially interfacial, and coupon failures.

In interfacial failure mode, Figure 10(a), a crack initiated from the nugget edge in the load bearing side of the nugget and along the loading direction. The crack then propagated through the nugget until separation of the coupons, while crack growth through the coupon thickness was also observed. Therefore, the fatigue strength in this mode of failure depends mainly on the size and strength of the nugget. This failure mode was observed only when very high cyclic loads were applied. 
Coupon failure, shown in Figure 10(c), was the most common mode of failure in tensile-shear loading of spot welds. In this failure mode, the crack started either from the BM-HAZ interface or from the BM, with an offset from the nugget edge, depending on the load level. This issue will be discussed in detail in the section 3.6. The crack in this mode then propagated through the coupon thickness and extended perpendicular to loading direction, until coupons separated. Fatigue life is therefore independent of nugget strength, but rather depends on cyclic loading level and dimensional parameters, such as nugget size and sheet thickness. Coupon failure was observed at lower loads, in intermediate and high cycle regimes.

Partially interfacial failure was a rare mode of failure under cyclic loading, and occurred only as a transition between interfacial and coupon failures. Cracks in this mode, as shown in Figure 10(b), nucleated from the same location as for interfacial failure, and grew first inside the nugget and then through the sheet thickness, following the bonding area. It can be seen that, similar to interfacial failure, there was another crack in this mode through the thickness, which was not as critical as the main crack. This mode of failure was observed in a narrow region between very low and low cycle regimes, i.e. when fatigue life was between $3 \times 10^{3}$ and $10^{4}$ cycles.

The different failure modes under cyclic loading can be described in terms of crack propagation through load analysis. In the high cycle regime, where a small load is cyclically applied to the specimens, as shown in Figure 11(a) the component of load on the "n-plane", $P_{n}$, dominates and because the area of the nugget is similar in size to the cross-sectional area of the coupon, it can be concluded that the mode I stress intensity factor (SIF) is larger on the n-plane. On the other hand, the mode I SIF is usually considered the main factor controlling crack growth rate for tensile-shear spot welds [28, 31]. Therefore, the load components in the $\mathrm{t}$ - and $\mathrm{n}$-planes can be considered as major parameters determining crack propagation rates, and in the case of $\mathrm{HCF}$, the crack propagates faster on the n-plane.

Under high cyclic loads, however, bending is more appreciable and the load component on the t-plane $\left(P_{t}^{\prime}\right)$ becomes comparable to that on the n-plane $\left(P_{n}^{\prime}\right)$. Therefore, the stress intensity factors corresponding 
to these two planes are similar and the cracks grow with similar rates. As the applied load is increased, the chance of interfacial failure rises which can be seen in Figure 10(a) and at lower loads, where the stress intensities are of the same magnitude, mixed mode failure on both the $\mathrm{t}$ - and n-planes may occur, Figure 10(b). The through-thickness cracks in the interfacial and partially interfacial failure modes are evidence of this issue. At very high loads, where the specimen fails in the first loading reversal, i.e. static tests, due to severe bending in coupons, failure happens on the t-plane without a crack on the n-plane (see Figure 8).

\subsection{Welding parameters effects}

Five sets of specimens, as listed in Table 3, were studied to investigate the effects of welding parameters on magnesium spot welds characteristics.

\section{Hardness}

The micro-indentation hardness distribution was obtained for three specimen sets A, C, and E, and the results are shown in Figure 12. To compare the hardness profiles for the different nugget sizes in these specimens, hardness values were plotted versus the ratio of the distance from the nugget center to the indentation point $(d)$ to the distance from the nugget center to the FZ boundary $\left(d_{F Z}\right)$, as shown in Figure 7(a). As can be seen, the hardness profile and hence the strength of the weld region is almost independent of the welding parameters.

\section{Quasi-static behavior}

To study the effect of welding parameters on strength and failure mode under monotonic loading, quasistatic tensile testing was performed on the five specimen sets listed in Table 3. Average and standard deviation values for ultimate tensile-shear load (UTSL) are summarized in Table 4. As expected, the UTSL of spot welds depends on nugget size, which is controlled by welding current and welding time; increasing each of these parameters enlarges the spot weld nugget and increases the UTSL.

As shown in Figure 13, the test results show that there is a linear relationship between UTSL and the nugget diameter of $\mathrm{Mg}$ spot welds. The same correlation has already been reported in the literature for 
aluminum [48, 59-60] and steel [47]. An interesting point is that the trend line slope is $1 \mathrm{kN} / \mathrm{mm}$ for both magnesium and aluminum spot welds, and is $3 \mathrm{kN} / \mathrm{mm}$ for steel spot welds, confirming that the UTSL in spot welds of steel is more sensitive to nugget size than for magnesium and aluminum.

The same failure modes as mentioned in section 3.3 for specimens in set $\mathrm{C}$ were observed for other specimen sets. Most specimens, i.e. 23 out of 25 specimens, failed in the interfacial mode and only 2 specimens failed in the partially interfacial mode, which means that welding parameters do not control the mode of failure. Also, considering the minimal effect of process parameters on hardness in the FZ (see Figure 12), increasing UTSL with welding current and time are attributed only to the different nugget size.

\section{Cyclic behavior}

Specimen sets A, C, and E were selected for fatigue testing to study the effect of nugget size on cyclic behavior. The fatigue life experimental data and the corresponding Load-life (L-N) curves obtained from the best fit bi-linear regression are shown in Figure 14.

According to this diagram, the nugget size effect on the fatigue resistance is appreciable in the low cycle regime, i.e. up to $10^{4}$ cycles. However, in the high cycle regime, a minimal enhancement in fatigue strength was achieved by enlarging the spot weld nugget. The endurance limit was $0.42 \mathrm{kN}, 0.55 \mathrm{kN}$, and $0.6 \mathrm{kN}$ for sets $\mathrm{A}, \mathrm{C}$, and $\mathrm{E}$, respectively.

Similar effects have been reported for steel $[47,61]$ and aluminum [48], however, recent research reported that increasing the nugget size resulted in decreasing the fatigue strength of spot welds in AISI304 stainless steel [62]. 


\subsection{Cyclic loading effects}

\section{Microstructure}

Figure 15 shows the microstructures of the $\mathrm{BM}, \mathrm{HAZ}$ and $\mathrm{FZ}$ on samples which failed under low and high cyclic loads, i.e. HCF, and LCF, respectively. Comparing these microstructures with Figure 3, Figure 4 and Figure 6 reveals that cyclic loading does not have a significant effect on the microstructures in the $\mathrm{BM}$ and the weld region, in terms of the shape and size of grains/dendrites. The same observation has been reported for steel spot welds [49].

\section{Hardness}

The graphs in Figure 16 compare the hardness profiles for specimens in sets A, C and E under three loading conditions, i.e. before loading and failed in the low and high cycle regimes. Hardness tests in all cases were performed from the weld center to the BM on one side. "BL" in the graph legend denotes the "before loading" condition.

The profiles in this figure show that hardness does not appreciably vary before and after cyclic loading, which agrees with the insignificant effect of cyclic loading on the microstructure. Therefore, it is expected that the BM and the weld area do not show a cyclic softening or hardening behaviour. This is similar to advanced high strength steels (AHSS) spot welds, but is in contrast to high strength low alloy (HSLA) steel spot welds, which show cyclic softening behaviour in the weld region under high cyclic loads [49].

\section{Crack-initiation/propagation}

Along with the goal of characterizing fatigue of $\mathrm{Mg}$ spot welds, the effect of cyclic loading on the fatigue crack initiation point was investigated. As shown in Figure 17, the distance between the nugget edge and the crack initiation site was considered as the comparison criterion, as it is independent of nugget diameter and represents the location of maximum local strain from the bond region. 
The distance "L" was measured in various specimens from sets A, C, and E, and the results are summarized in Figure 18. The graph shows that in the 3 specimen sets under investigation, the crack initiation point was closer to the nugget edge under high cyclic loading, and as the cyclic load decreased, cracks initiated farther from the nugget. Cracks in all specimens which failed in LCF nucleated inside the $\mathrm{HAZ}$ or at the interface of the HAZ and BM, while in specimens which failed in HCF, cracks initiated in the BM. One of the reasons why nugget size had no significant effect on fatigue resistance in the high cycle regime (see Figure 14) was that crack initiation happened far from the FZ and therefore nugget size or stress concentration did not have as much of an effect on the stress field at the crack nucleation site.

In terms of fatigue crack propagation, the crack length was measured on the cross-section passing through the center of the spot welds in different specimens and under low and high cyclic loads. Studying the spot weld cross-section revealed that there were two cracks on most samples, one on each coupon, on the load bearing side of the weld. In failed specimens, the crack which caused separation in the specimen was referred to as the "primary crack" and the other crack, which was on the opposite side of the weld, was called the "secondary crack". Figure 19 shows the primary and secondary cracks in two specimens in set C, under different cyclic loading conditions.

Figure 19(a) illustrates that in the low cycle regime the secondary crack has propagated through the whole coupon thickness, while in the high cycle regime it has only propagated a portion of the sheet thickness. Table 5 summarizes the crack propagation length in the three sets under investigation, in both low and high cycle regimes.

In the specimens which did not fail, i.e. run-out specimens, no crack was initiated on either side, suggesting that the crack initiation life is a significant portion of the total fatigue life for spot welds in the high cycle regime.

In terms of primary crack propagation, there was a dependence between the propagation path and cyclic loading amplitude. The primary crack under high cyclic loads, as shown in Figure 20(a), grew through the 
coupon thickness normal to the sheet surface and followed the nugget circular shape in the plane of the sheet, finally extending through the coupon width perpendicular to the loading direction.

Figure 20(b) shows the crack propagation path under lower loads, i.e. the intermediate cycle regime, which was similar to high loads, except that along the thickness the crack tended towards the nugget and did not follow the nugget shape as much in the plane of the sheet. For loads just above the endurance

limit, i.e. lives more than $5 \times 10^{5}$ cycles, as shown in Figure 20(c), crack growth through the thickness was on a curved path and then propagated along the coupon width, almost along a straight line, with an offset from the nugget.

\section{Conclusions}

Magnesium spot weld behavior in tensile-shear configuration was studied under both monotonic and cyclic loading. Where possible, magnesium spot weld behavior was compared to that of steel and aluminum spot welds. The following conclusions can be drawn from this study:

1. Interfacial and partially interfacial are the failure modes under monotonic loading. Cyclic loadings depending on the load level may cause large, intermediate or small bending on coupons, which results in different stress intensity factors for through-thickness- and though-nugget-cracks causing interfacial, partially interfacial, or coupon failures.

2. Similar to spot welds in steel and aluminum, there is a linear relationship between ultimate tensile shear load and nugget diameter for magnesium spot welds. This trend is estimated at $1 \mathrm{kN} / \mathrm{mm}$ for the alloy investigated.

3. Nugget size has a significant effect on fatigue resistance for magnesium spot welds in the low cycle regime; however, its effect gradually decreases over the life such that for lives over $10^{5}$ cycles, the fatigue strength is almost independent of nugget size. 
4. Cyclic loading does not have a significant effect on hardness of the base metal, heat-affected and fusion zones, suggesting that the base metal and weld region do not exhibit cyclic hardening or softening behavior.

5. Fatigue crack initiation location depends on the load level. Under high cyclic loading, cracks initiate close to the nugget edge and decreasing the cyclic load causes the cracks to initiate farther from the nugget.

6. Two cracks initiate at opposite sides of the nugget under cyclic loading, one that grows to fail the specimen (primary crack), and the other that propagates considerably but does not cause the failure (secondary crack).

7. The secondary crack length depends on both nugget size and cyclic load level. In the low cycle regime, the secondary crack propagates through the entire thickness. In the high cycle regime, the secondary crack length decreases by enlarging nugget. In run-out specimens, no crack was detected on either side of the weld, which means that the crack initiation life is a significant portion of the total fatigue life of spot welds in the high cycle regime.

8. Primary crack propagation path is controlled by cyclic loading amplitude. High loading amplitudes result in crack growth normal to the sheet plane, following the nugget shape and propagating perpendicular to the loading direction. Primary cracks under intermediate cyclic loading follow the nugget elliptical curvature through the thickness but do not trace the nugget circular shape as much in the coupon plane. Small loading amplitudes make the cracks grow through the thickness on a curved path, and almost straight along the coupon width, perpendicular to the loading direction.

\section{Acknowledgements}

This research was performed as a part of the Magnesium Front End Research and Development (MFERD) which is a multi-national project involving universities and companies from Canada, China, and US. The authors would like to acknowledge AUTO21 for financial support and General Motors for 
providing AZ31B magnesium sheets. The collaboration of the resistance spot welding laboratory of the University of Waterloo for providing spot weld specimens is also appreciated.

\section{References}

[1] Kulekci MK. Magnesium and its alloys applications in automotive industry. International Journal of Advanced Manufacturing Technology. 2008;39:851-65.

[2] Chen W, Ackerson P, Molian P. CO2 laser welding of galvanized steel sheets using vent holes. Materials \& Design. 2009;30:245-51.

[3] Aslanlar S, Ogur A, Ozsarac U, Ilan E. Welding time effect on mechanical properties of automotive sheets in electrical resistance spot welding. Materials \& Design. 2008;29:1427-31.

[4] Ion JC. Laser beam welding of wrought aluminium alloys. Science and Technology of Welding and Joining. 2000;5:265-76.

[5] Aydin H, Bayram A, Uguz A, Akay KS. Tensile properties of friction stir welded joints of 2024 aluminum alloys in different heat-treated-state. Materials \& Design. 2009;30:2211-21.

[6] Torkamany MJ, Tahamtan S, Sabbaghzadeh J. Dissimilar welding of carbon steel to 5754 aluminum alloy by Nd:YAG pulsed laser. Materials \& Design. 2010;31:458-65.

[7] Taban E, Gould JE, Lippold JC. Dissimilar friction welding of 6061-T6 aluminum and AISI 1018 steel: Properties and microstructural characterization. Materials \& Design. 2010;31:2305-11.

[8] Zhang ZD, Liu LM, Sun H, Wang L. AC TIG welding with single-component oxide activating flux for AZ31B magnesium alloys. Journal of Materials Science. 2008;43:1382-8.

[9] Weisheit A, Galun R, Mordike BL. CO2 laser beam welding of magnesium-based alloys. Welding Journal. 1998;77:149S-54S.

[10] Kim TW, Kim JC, Hasegawa Y, Suga Y. Welding of AZ31B magnesium alloy by YAG laser/TIG arc hybrid welding process. Designing, Processing and Properties of Advanced Engineering Materials, Pts 1 and 2. 2004;449-4:417-20.

[11] Esparza JA, Davis WC, Trillo EA, Murr LE. Friction-stir welding of magnesium alloy AZ31B. Journal of Materials Science Letters. 2002;21:917-20.

[12] Lang B, Sun DQ, Li GZ, Qin XF. Effects of welding parameters on microstructure and mechanical properties of resistance spot welded magnesium alloy joints. Science and Technology of Welding and Joining. 2008;13:698-704.

[13] Qiu RF, Satonaka S, Iwamoto C. Mechanical properties and microstructures of magnesium alloy AZ31B joint fabricated by resistance spot welding with cover plates. Science and Technology of Welding and Joining. 2009;14:691-7.

[14] Rathbun RW, Matlock DK, Speer JG. Fatigue Behavior of spot welded high-strength sheet steels. Welding Journal. 2003;82:207S-18S.

[15] Gao Y, Chucas D, Lewis C, McGregor IJ. Review of CAE Fatigue Analysis Techniques for SpotWelded High Strength Steel Automotive Structures. SAE 2001 World Congress. Detroit, MI, USA2001.

[16] Kang HT. Fatigue prediction of spot welded joints using equivalent structural stress. Materials \& Design. 2007;28:837-43. 
[17] Hilditch TB, Speer JG, Matlock DK. Effect of susceptibility to interfacial fracture on fatigue properties of spot-welded high strength sheet steel. Materials \& Design. 2007;28:2566-76.

[18] Park JM, Kang HT. Prediction of fatigue life for spot welds using back-propagation neural networks. Materials \& Design. 2007;28:2577-84.

[19] Kim DH, Kim HK. Fatigue strength evaluation of cross-tension spot weld joints of cold rolled mild steel sheet. Materials \& Design. 2009;30:3286-90.

[20] Radaj D. STRESS SINGULARITY, NOTCH STRESS AND STRUCTURAL STRESS AT SPOTWELDED JOINTS. Engineering Fracture Mechanics. 1989;34:495-506.

[21] Sheppard SD, Strange M. FATIGUE LIFE ESTIMATION IN RESISTANCE SPOT WELDS: INITIATION AND EARLY GROWTH PHASE. Fatigue \& Fracture of Engineering Materials \& Structures. 1992;15:531-49.

[22] Pan N. Fatigue life study of spot welds: Stanford University; 2000.

[23] Nakahara Y, Takahashi M, Kawamoto A, Fujimoto M, N. T. Method of Fatigue Life Estimation for Spot-Welded Structures. SAE 2000 World Congress. Detroit, MI, USA2000.

[24] Radaj D. Design and analysis of fatigue resistant welded structures. Abington, Cambridge: Woodhead Publishing Ltd.; 1990.

[25] Kan YR. FATIGUE RESISTANCE OF SPOTWELDS - ANALYTICAL STUDY. Metals Engineering Quarterly. 1976;16:26-36.

[26] Oh HL. Fatigue-life prediction for spotweld using Neubers rule. Design of fatigue and fracture resistance structures. Philadelphia, PA: American Society for Testing and Materials; 1982. p. 296-309.

[27] Pan N, Sheppard S. Spot welds fatigue life prediction with cyclic strain range. International Journal of Fatigue. 2002;24:519-28.

[28] Pook LP. FRACTURE MECHANICS ANALYSIS OF THE FATIGUE BEHAVIOUR OF SPOT WELDS. International Journal of Fracture. 1975;11:173-6.

[29] Swellam MH, Kurath P, Lawrence FV. ELECTRIC-POTENTIAL-DROP STUDIES OF FATIGUE CRACK DEVELOPMENT IN TENSILE-SHEAR SPOT WELDS. Advances in Fatigue Lifetime Predictive Techniques. Philadelphia, PA1992. p. 383-401.

[30] Davidson JA, Imhof EJ. A Fracture-Mechanics and System-Stiffness Approach to Fatigue Performance of Spot-Welded Sheet Steels. SAE Congress. Detroit, Michigan, USA1983.

[31] Sheppard SD. ESTIMATION OF FATIGUE PROPAGATION LIFE IN RESISTANCE SPOT WELDS. Advances in Fatigue Lifetime Predictive Techniques1993. p. 169-85.

[32] Sheppard SD. Further refinement of a methodology for fatigue life estimation in resistance spot weld connections. Advances in Fatigue Predictive Techniques. Philadelphia1996. p. 265-82.

[33] Newman JA, Dowling NE. A crack growth approach to life prediction of spot-welded lap joints. Fatigue \& Fracture of Engineering Materials \& Structures. 1998;21:1123-32.

[34] Wang PC, Ewing KM. A COMPARISON OF FATIGUE STRENGTHS - LASER-BEAM VS RESISTANCE SPOT WELDS. Welding Journal. 1991;70:43-7.

[35] Uematsu Y, Tokaji K. Comparison of fatigue behaviour between resistance spot and friction stir spot welded aluminium alloy sheets. Science and Technology of Welding and Joining. 2009;14:62-71.

[36] Long X, Khanna SK. Fatigue performance of spot welded and weld bonded advanced high strength steel sheets. Science and Technology of Welding and Joining. 2008;13:241-7. 
[37] Sun X, Stephens EV, Khaleel MA, Shao H, Kimchi M. Resistance spot welding of aluminum alloy to steel with transition material - From process to performance - Part 1: Experimental study - Weld strength, failure mode, and fatigue life were compared with self-piercing rivets of the same dissimilar metals combination. Welding Journal. 2004;83:188S-95S.

[38] Overbeeke JL, Draisma J. INFLUENCE OF STRESS RELIEVING ON FATIGUE OF HEAVYDUTY SPOT WELDED LAP JOINTS. Metal Construction. 1978;10:433-4.

[39] Kim D, Blake D, Ryu SJ, Lim BS. A study on fatigue strength improvement of aluminum alloy resistant spot welds by cold working. In: Chandra T, Tsuzaki K, Militzer M, Ravindran C, editors. THERMEC 2006, Pts 1-5. Stafa-Zurich: Trans Tech Publications Ltd; 2007. p. 3961-6.

[40] Kim D, Blake DM, Ryu SJ, Lim BS. Improvement of fatigue life in post-weld cold worked aluminum resistant spot welds. International Journal of Automotive Technology. 2006;7:579-84.

[41] Kim D, Spitsen R, Khosla T, Li W, Ryu S, Lim B. A study on cold working of aluminum spot welds to improve fatigue strength. Transactions of the North American Manufacturing Research Institution of SME. 2005;33:251-8.

[42] Spitsen R, Kim D, Flinn B, Ramulu M, Easterbrook ET. The effects of post-weld cold working processes on the fatigue strength of low carbon steel resistance spot welds. Journal of Manufacturing Science and Engineering-Transactions of the Asme. 2005;127:718-23.

[43] Chang BH, Du D, Sui B, Zhou Y, Wang Z, Heidarzadeh F. Effect of forging force on fatigue behavior of spot welded joints of aluminum alloy 5182. Journal of Manufacturing Science and Engineering-Transactions of the Asme. 2007;129:95-100.

[44] Barkey ME, Kang H, Lee YL. Failure modes of single resistance spot welded joints subjected to combined fatigue loading. International Journal of Materials \& Product Technology. 2001;16:510-27.

[45] Iyengar RM, Laxman S, Amaya M, Citrin K, Bonnen J, Kang HT, et al. Influence of Geometric Parameters and Their Variability on Fatigue Resistance of Spot-Weld Joints. SAE Int J Mater Manuf. 2008;1:299-316.

[46] Ertas AH, Sonmez FO. A parametric study on fatigue strength of spot-weld joints. Fatigue \& Fracture of Engineering Materials \& Structures. 2008;31:766-76.

[47] Pollard B. Fatigue strength of spot welds in titanium-bearing HSLA steels. SAE Congress. Detroit, Michigan, USA1982.

[48] Gean A, Westgate SA, Kucza JC, Ehrstrom JC. Static and fatigue behavior of spot-welded 5182-0 aluminum alloy sheet. Welding Journal. 1999;78:80S-6S.

[49] Long X, Khanna SK. Fatigue properties and failure characterization of spot welded high strength steel sheet. International Journal of Fatigue. 2007;29:879-86.

[50] Behravesh SB, Liu L, Jahed H, Lambert S, Glinka G, Zhou Y. Effect of Nugget Size on Tensile and Fatigue Strength of Spot Welded AZ31 Magnesium Alloy. SAE 2010 World Congress. Detroit, Michigan, USA: SAE International; 2010.

[51] Liu L, Zhou SQ, Tian YH, Feng JC, Jung JP, Zhou YN. Effects of surface conditions on resistance spot welding of Mg alloy AZ31. Science and Technology of Welding and Joining. 2009;14:356-61.

[52] Afrin N, Chen DL, Cao X, Jahazi M. Microstructure and tensile properties of friction stir welded AZ31B magnesium alloy. Materials Science and Engineering a-Structural Materials Properties Microstructure and Processing. 2008;472:179-86.

[53] Cao X, Jahazi M, Immarigeon JP, Wallace W. A review of laser welding techniques for magnesium alloys. Journal of Materials Processing Technology. 2006;171:188-204. 
[54] Ma C, Chen DL, Bhole SD, Boudreau G, Lee A, Biro E. Microstructure and fracture characteristics of spot-welded DP600 steel. Materials Science and Engineering a-Structural Materials Properties Microstructure and Processing. 2008;485:334-46.

[55] Pereira AM, Ferreira JM, Loureiro A, Costa JDM, Bartolo PJ. Effect of process parameters on the strength of resistance spot welds in 6082-T6 aluminium alloy. Materials \& Design. 2010;31:2454-63.

[56] Person NL. Tensile-Shear and Fatigue Properties of Resistance and Mig Spot Welds of Some Al Auto Body Sheet Alloys. SAE International1975.

[57] Chao YJ. Ultimate strength and failure mechanism of resistance spot weld subjected to tensile, shear, or combined tensile/shear loads. Journal of Engineering Materials and Technology-Transactions of the Asme. 2003;125:125-32.

[58] Khan MI, Kuntz ML, Zhou Y. Effects of weld microstructure on static and impact performance of resistance spot welded joints in advanced high strength steels. Science and Technology of Welding and Joining. 2008;13:294-304.

[59] Thornton PH, Krause AR, Davies RG. The aluminum spot weld. Welding Journal. 1996;75:S101-S8.

[60] Ghorbani M, Assempour A. The Influence of Weld Current and Time on the Properties of Spot Welds in 5754 Aluminum Alloy Sheet. SAE 2002 World Congress \& Exhibition. Detroit, MI, USA: SAE; 2002.

[61] Davidson JA. A review of the fatigue properties of spot-welded sheet steels. SAE Congress. Detroit, Michigan, USA: SAE International; 1983.

[62] Vural M, Akkus A, Eryurek B. Effect of welding nugget diameter on the fatigue strength of the resistance spot welded joints of different steel sheets. Journal of Materials Processing Technology. 2006;176:127-32. 


\section{Figure Captions}

Figure 1: Tensile-shear specimen geometry (dimension are in $\mathrm{mm}$ )

Figure 2: different zones in AZ31B spot welds (a) low magnification (b) high magnification

Figure 3: Microstructure of the BM (a) in RD (b) in TD

Figure 4: Microstructure of HAZ in AZ31B spot welds (a) low magnification (b) high magnification

Figure 5: Microstructure of PMZ in AZ31B spot welds (a) low magnification (b) high magnification

Figure 6: Microstructure of FZ (a) overall (b) equiaxed dendrites in FZ-core

Figure 7: Vickers hardness (a) indentation path (b) hardness profile

Figure 8: Failure modes under tensile loading (a) interfacial (b) partially interfacial failure

Figure 9: Load-life data for spot welded specimens

Figure 10: Failure modes under cyclic loading (a) interfacial; (b) partially interfacial; (c) coupon failure

Figure 11: Tensile-shear specimen (a) under low load/in high cycle regime (b) under high load/in low cycle regime

Figure 12: Hardness profile comparison between specimen sets A, C, and E

Figure 13: effect of nugget diameter on UTSL

Figure 14: Load-life data for spot weld specimens

Figure 15: Cyclic loading effect on the microstructures

Figure 16: Hardness profiles before and after cyclic loading (a) set A (b) Set C (c) Set E

Figure 17: Crack initiation point (a) in LCF (b) in HCF

Figure 18: Distance between crack initiation point and nugget edge 
Figure 19: crack propagation in specimens in set C (a) in LCF (b) in HCF

Figure 20: Primary crack propagation path under (a) high load (b) intermediate load (c) low load 


\section{Tables}

Table 1: Chemical composition of AZ31B-H24 Mg alloy

\begin{tabular}{ccccl}
\hline Element & Al & Zn & Mn & Mg \\
\hline Weight $\%$ & 2.73 & 0.915 & 0.375 & Bal. \\
\hline
\end{tabular}

Table 2: Mechanical properties of AZ31B-H24 Mg alloy

\begin{tabular}{cccc}
\hline Direction & $\mathbf{0 . 2 \%}$ offset yield strength & Ultimate Tensile Strength & $\begin{array}{c}\text { Elongation } \\
(\mathbf{M P a})\end{array}$ \\
\hline Rolling (RD) & $224(3.5)^{*}$ & $292(0.6)$ & $14(3.0)$ \\
Transverse (TD) & $281(0.4)$ & $320(0.5)$ & $22(2.6)$ \\
\hline
\end{tabular}

* values in parentheses are standard deviations.

Table 3: RSW specimens coding and process parameters

\begin{tabular}{ccccc}
\hline $\begin{array}{c}\text { Specimen } \\
\text { Set }\end{array}$ & $\begin{array}{c}\text { Welding current } \\
(\mathbf{k A})\end{array}$ & $\begin{array}{c}\text { Welding Time } \\
(\mathbf{c y c l e})\end{array}$ & $\begin{array}{c}\text { Electrode force } \\
(\mathbf{k N})\end{array}$ & $\begin{array}{c}\text { Avg. Nugget Size } \\
(\mathbf{m m})\end{array}$ \\
\hline A & 26 & 10 & 4 & $8.2(0.7)^{*}$ \\
B & 28 & 8 & 4 & $8.6(0.4)$ \\
C & 30 & 8 & 4 & $9.5(0.1)$ \\
D & 32 & 8 & 4 & $9.8(0.1)$ \\
E & 34 & 8 & 4 & $10.4(0.2)$ \\
\hline
\end{tabular}

* values in parentheses are standard deviations.

Table 4: Ultimate Tensile Shear Load for different spot weld specimens

\begin{tabular}{lccccc}
\hline & Set A & Set B & Set C & Set D & Set E \\
\hline Mean UTSL[kN] & 5.12 & 5.73 & 6.67 & 7.15 & 7.75 \\
Std. Dev. [kN] & 0.22 & 0.30 & 0.16 & 0.10 & 0.35 \\
\hline
\end{tabular}

Table 5: Fatigue crack propagation under high and low cyclic loads

\begin{tabular}{ccl}
\hline Specimen & Loading Condition & \multicolumn{1}{c}{ Crack Propagation } \\
\hline \multirow{2}{*}{ Set A } & LCF & Cracks on both sides; SC * length $=\mathrm{t}^{* *}$ \\
& $\mathrm{HCF}$ & Cracks on both sides; SC length $=0.8 \mathrm{t}$ \\
& Run-out & No crack \\
\hline \multirow{2}{*}{ Set C } & LCF & Cracks on both sides; SC length $=\mathrm{t}$ \\
& $\mathrm{HCF}$ & Cracks on both sides; SC length $=0.3 \mathrm{t}$ \\
& Run-out & No crack \\
\hline \multirow{2}{*}{ Set E } & LCF & Cracks on both sides; SC length $=\mathrm{t}$ \\
& HCF & Crack on one side \\
& Run-out & No crack \\
\hline
\end{tabular}

* SC: Secondary Crack $\quad * *$ t: sheet thickness 

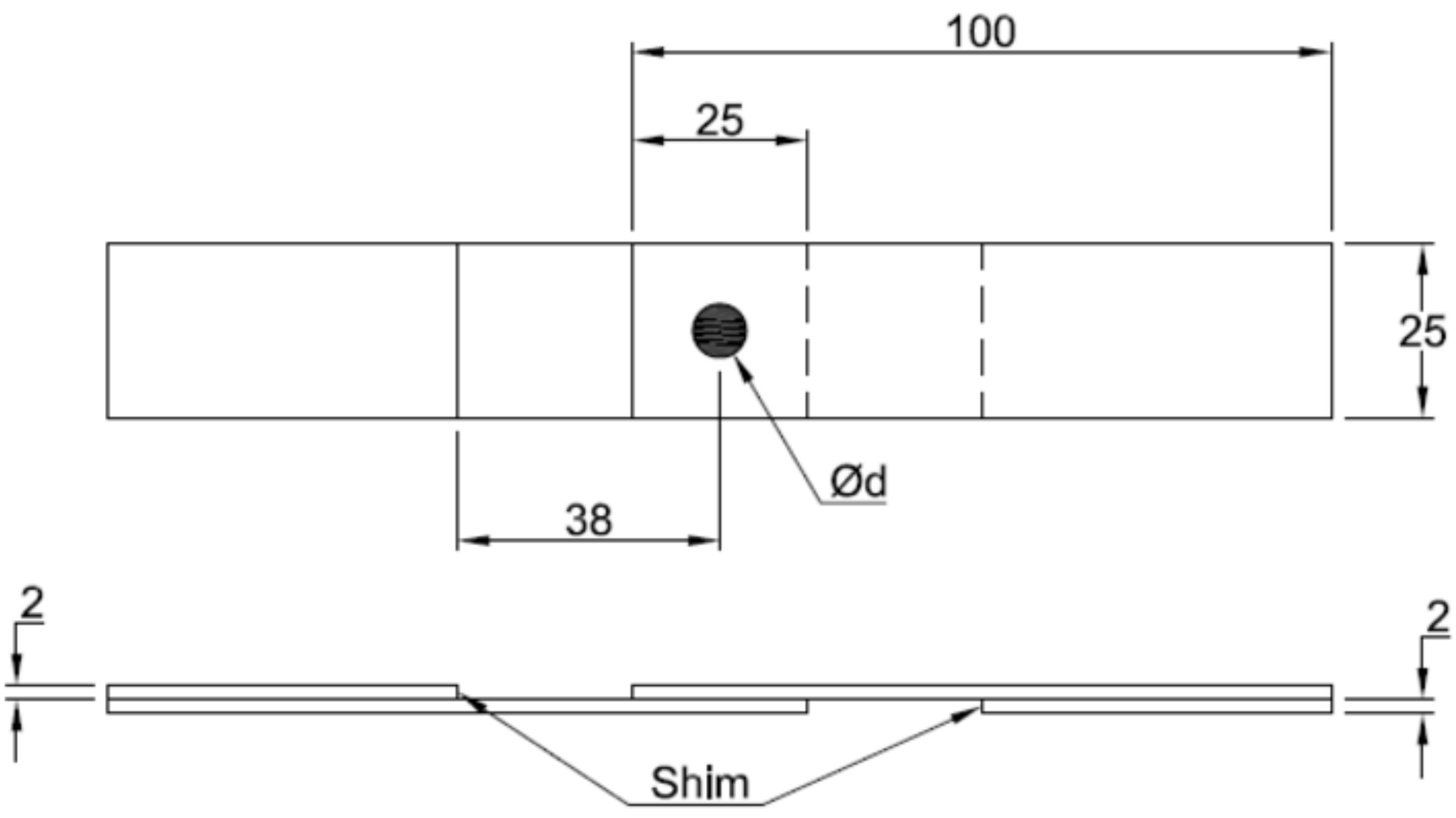
Click here to download high resolution image
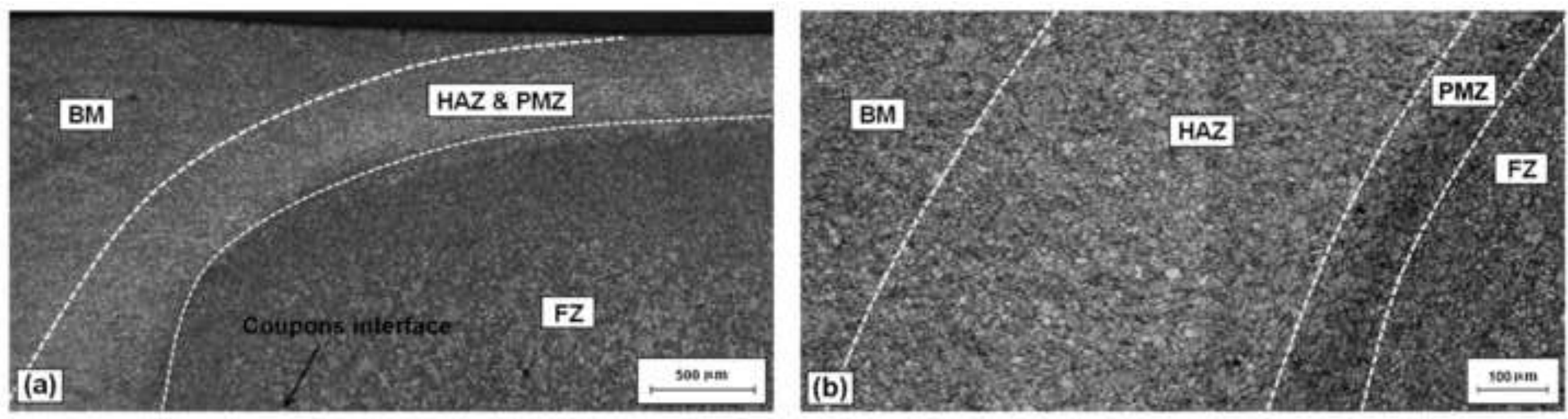
Click here to download high resolution image
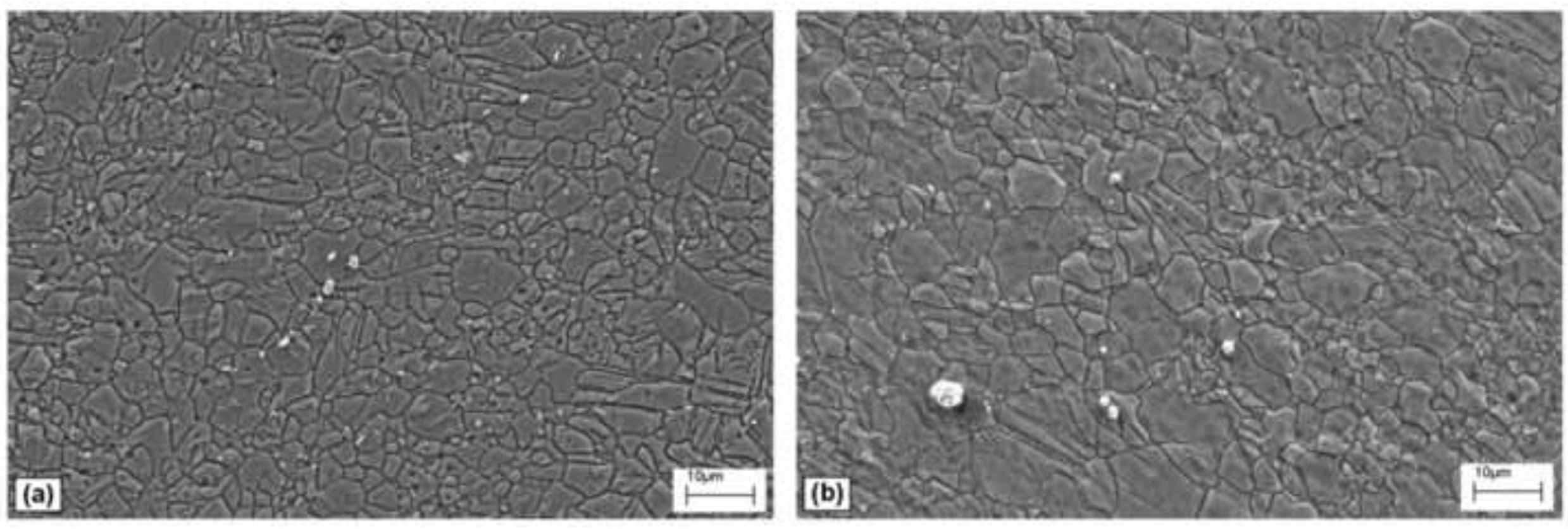

Figure 3 
Click here to download high resolution image
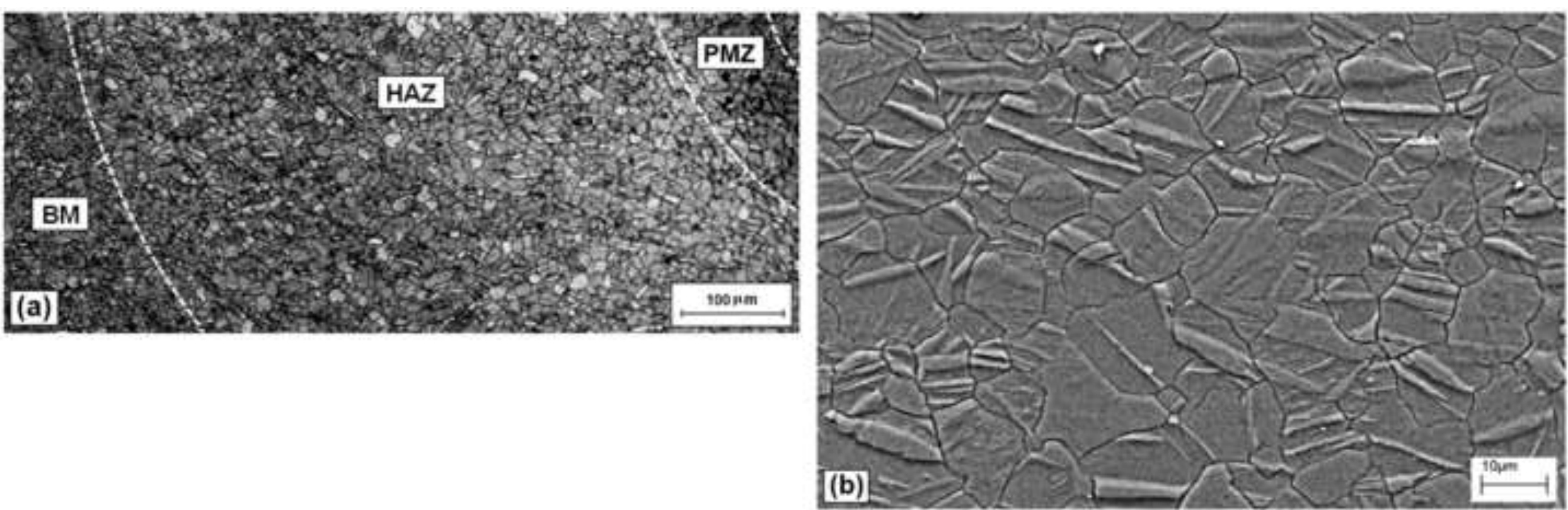
Click here to download high resolution image
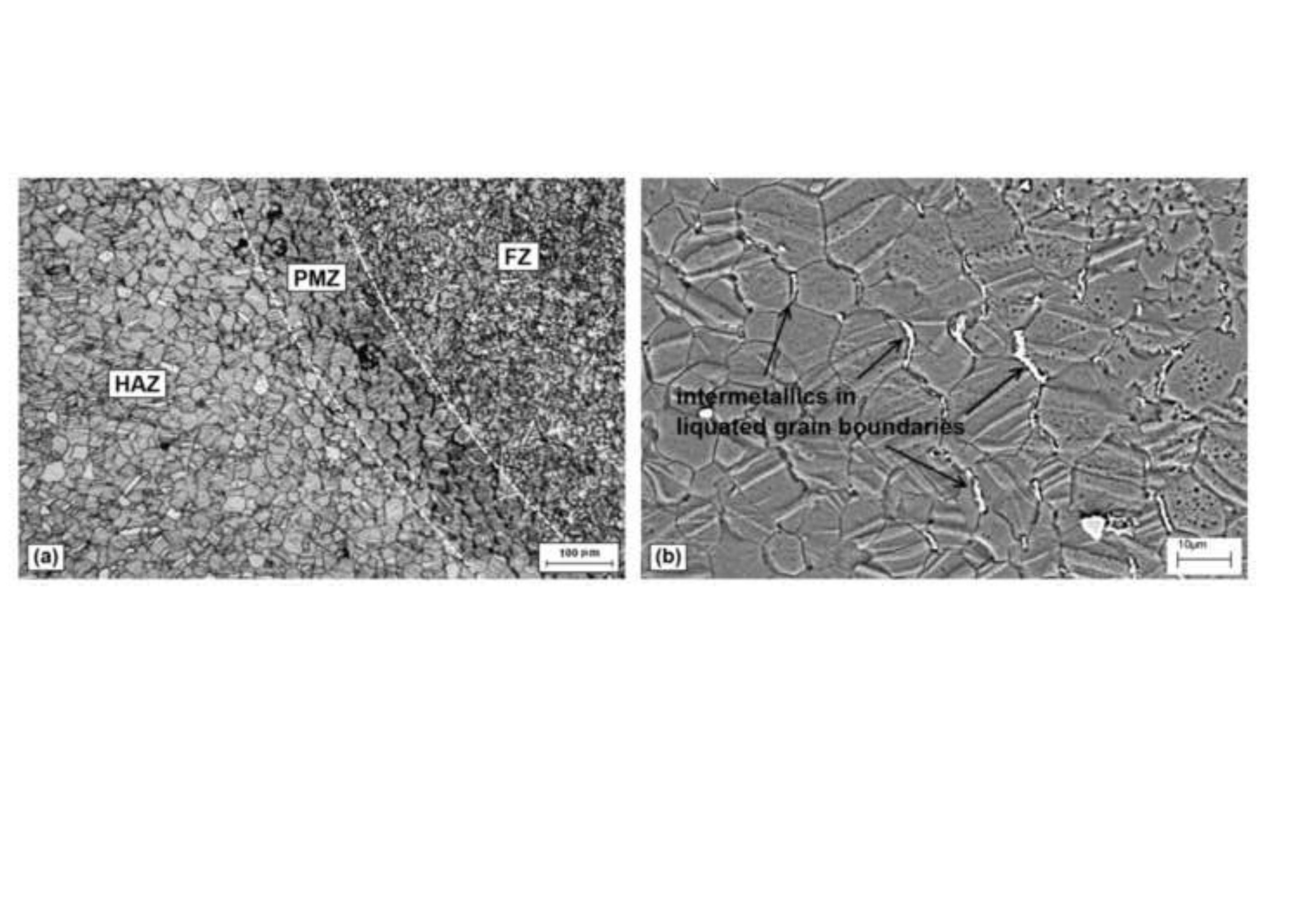

(2)
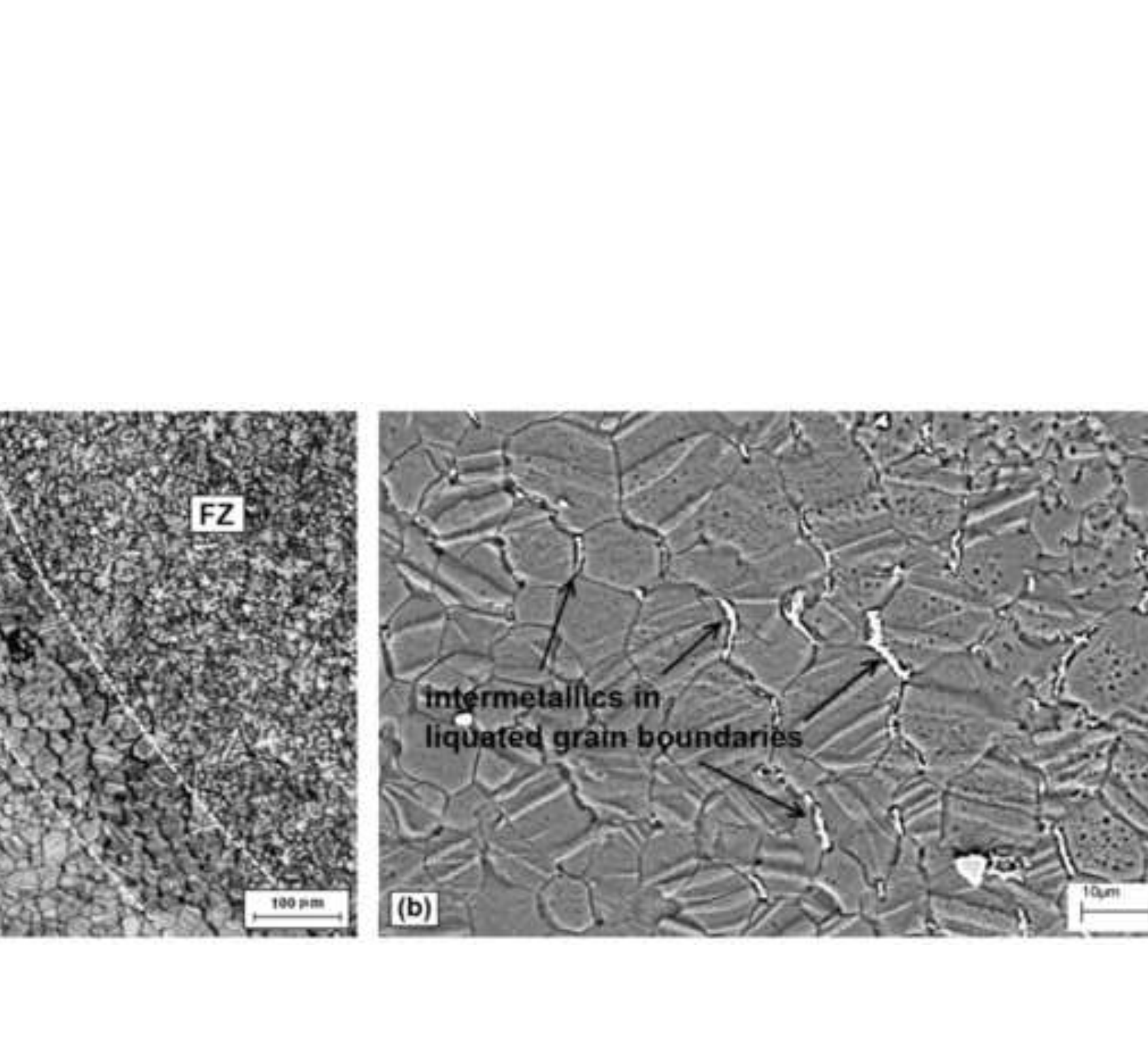

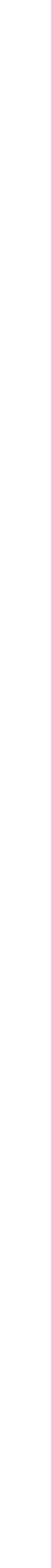


Click here to download high resolution image
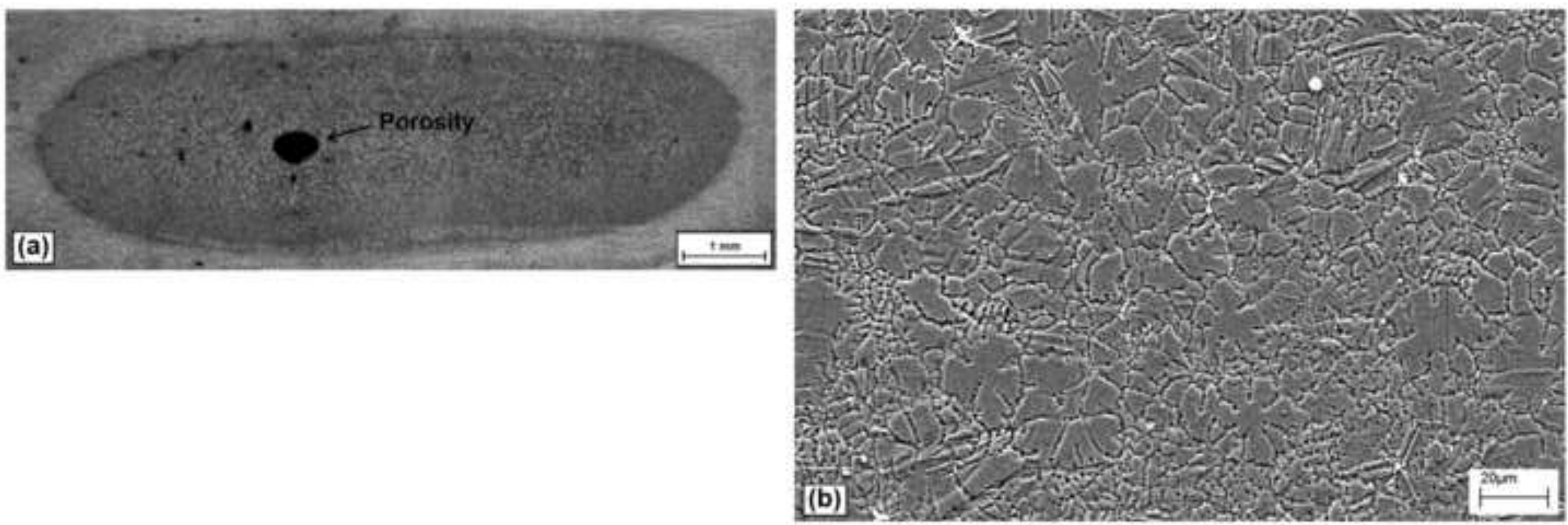


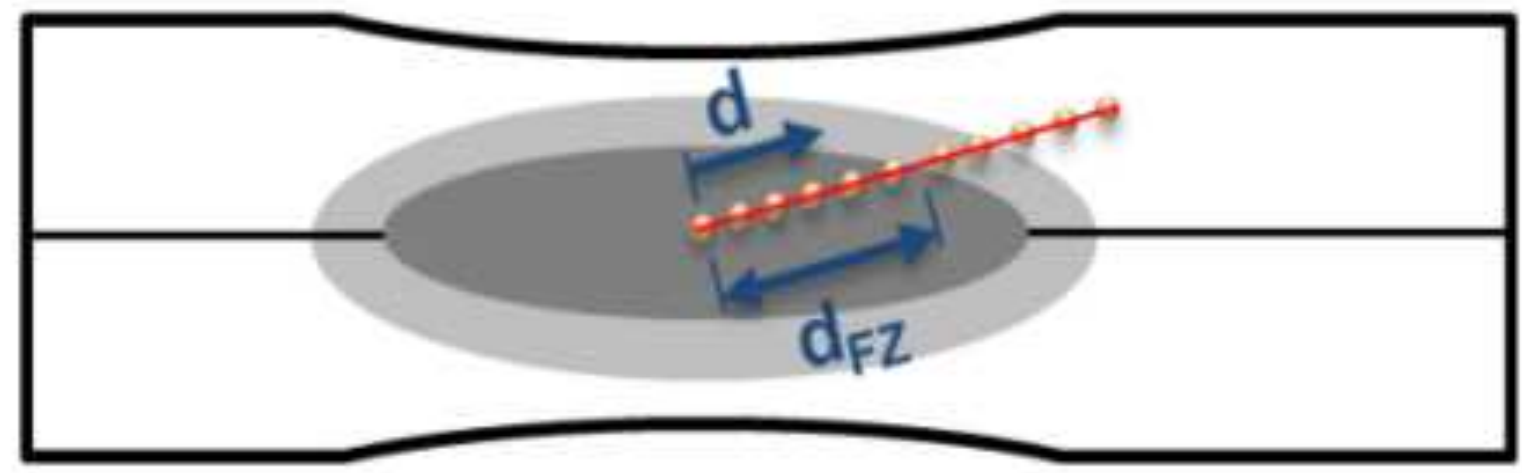

$\square$ Base Material

Heat Affected Zone

Fusion Zone

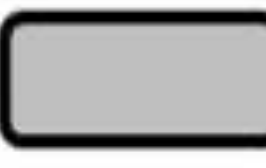


gure 7(a)-Grayscale (for print)

Click here to download high resolution image

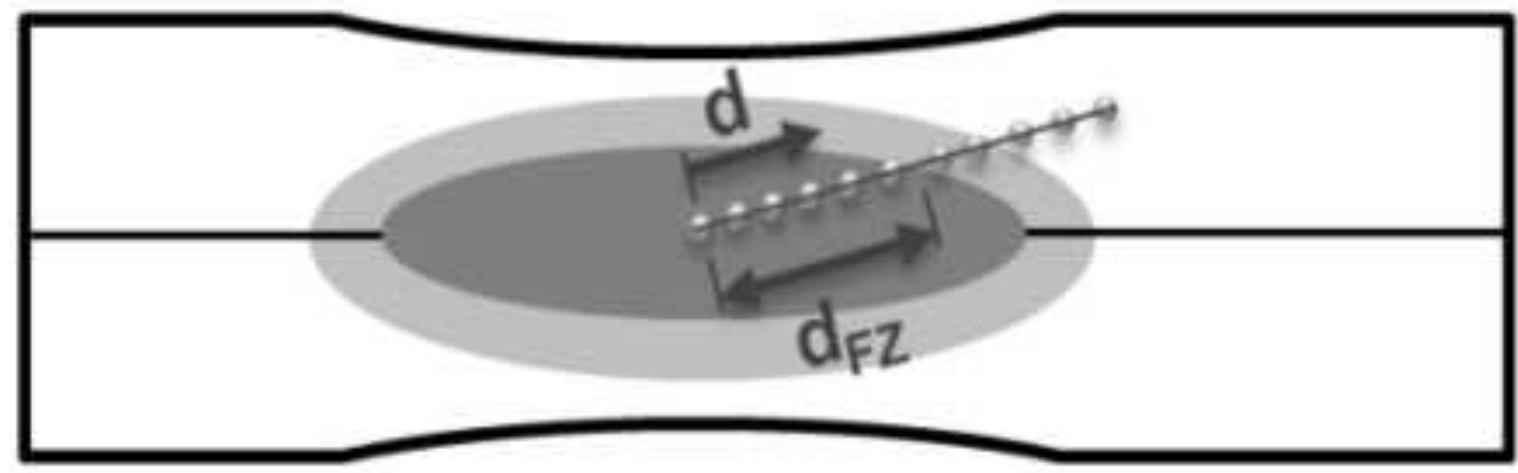

\section{Base Material}

Heat Affected Zone

Fusion Zone
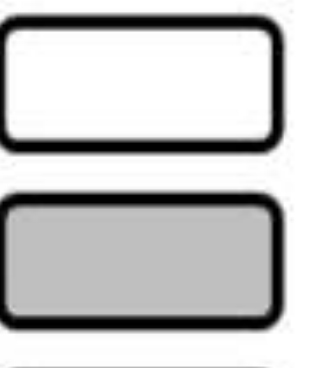
Figure 7(b)-Color (for Web only)

)

\section{)}

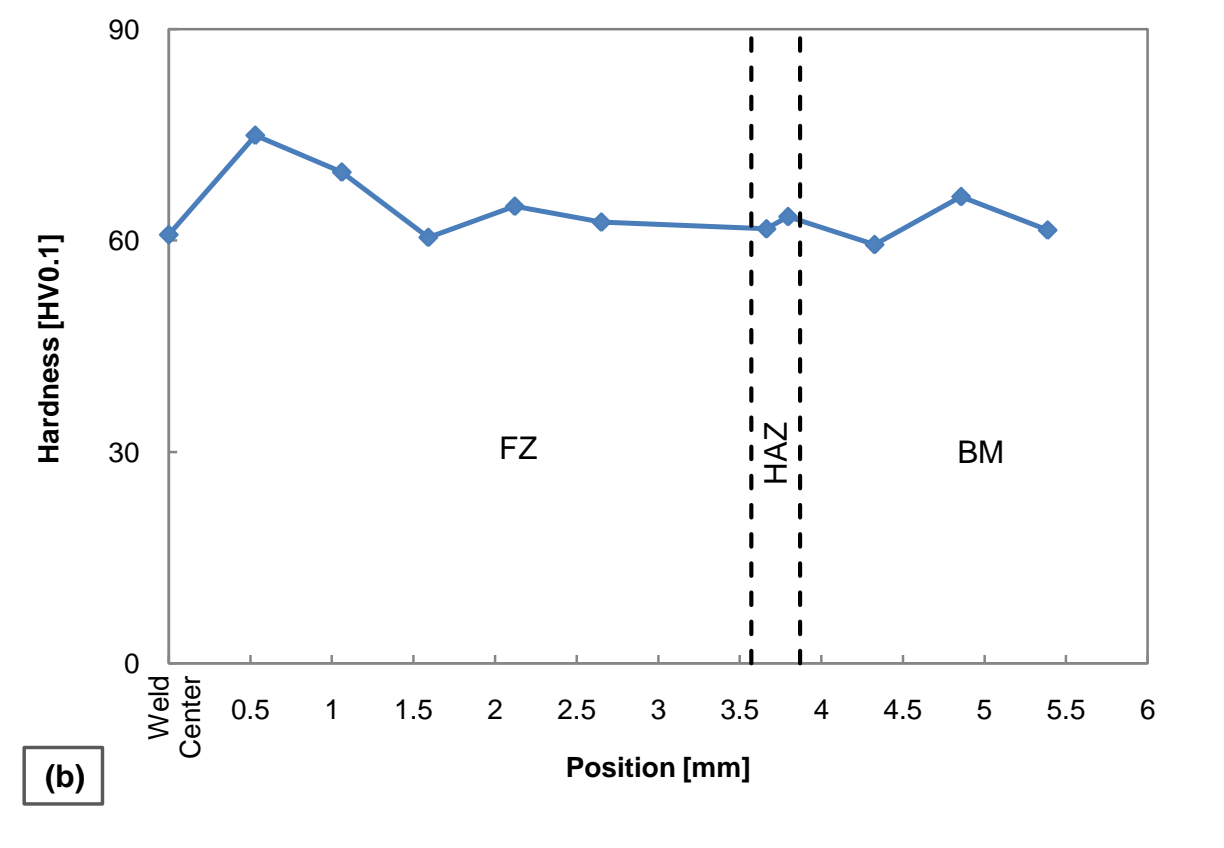

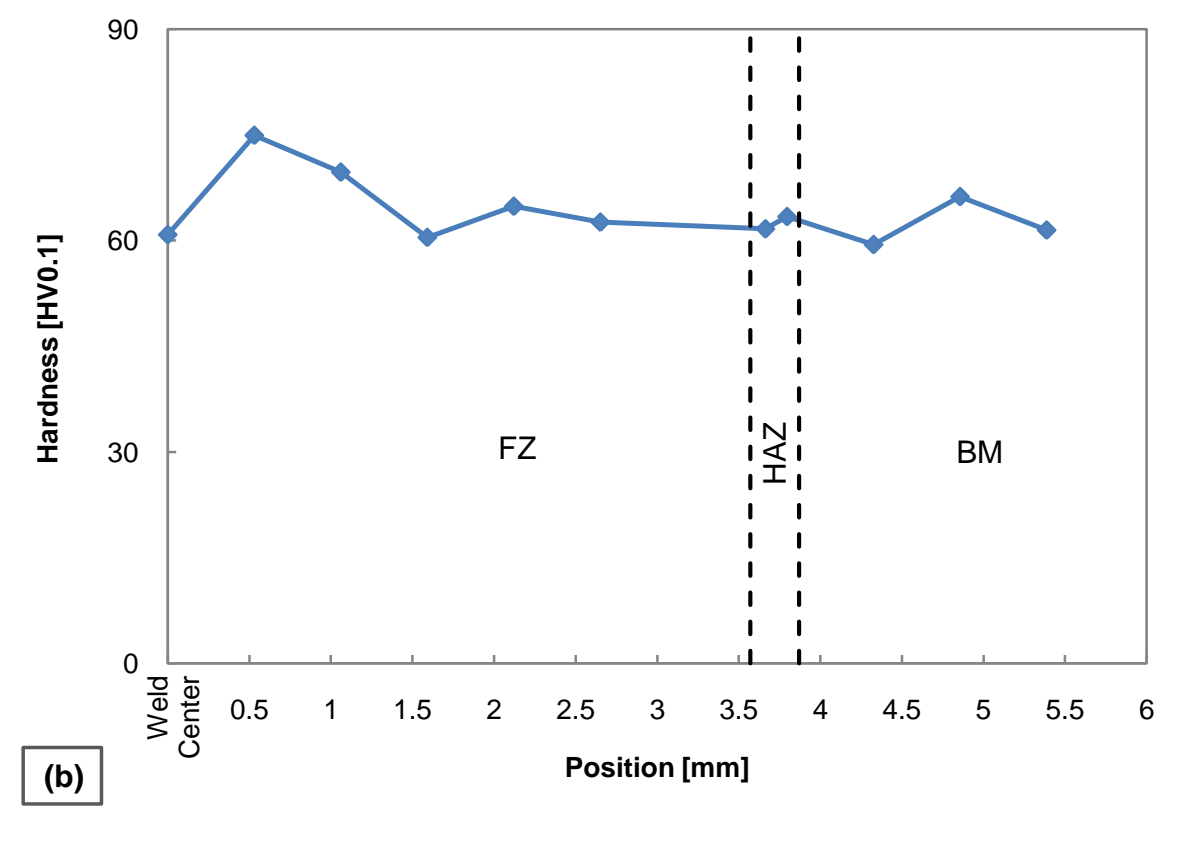

(b) 
Figure $7(b)$-Grayscale (for print)

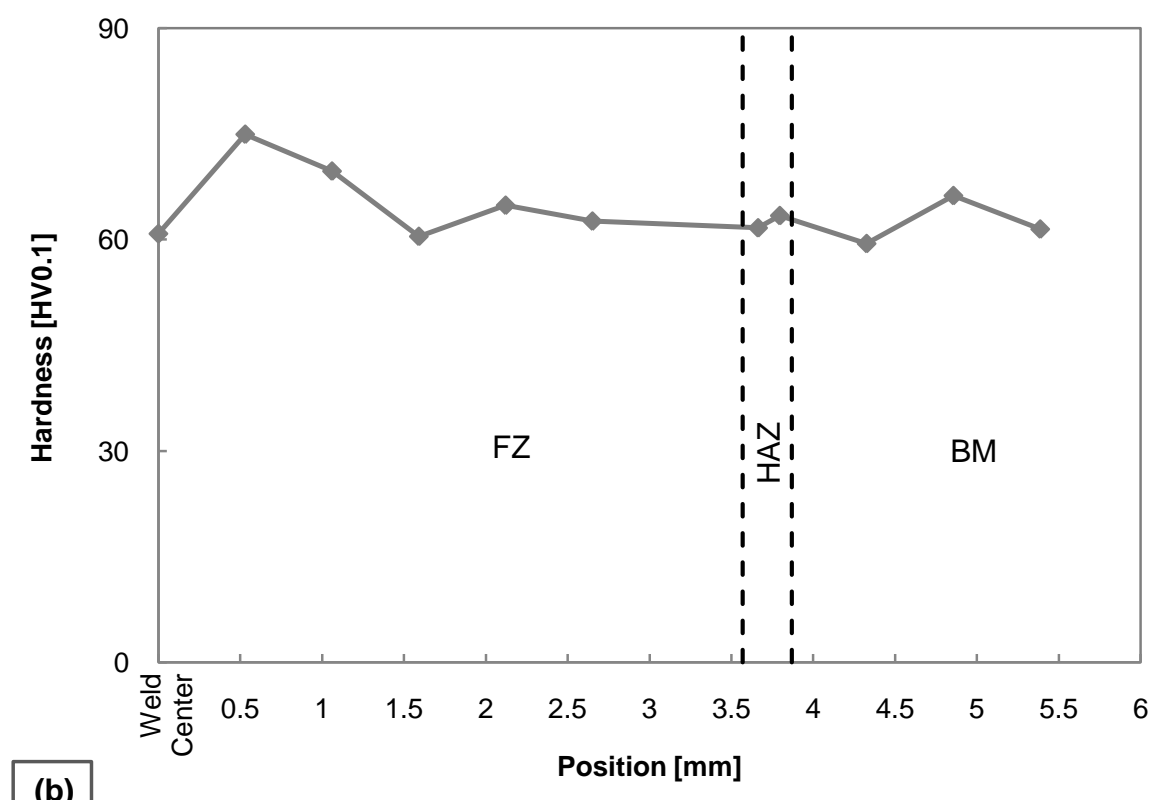

(b)

Position [mm] 
Flick here to download high resolution image
Clige 8
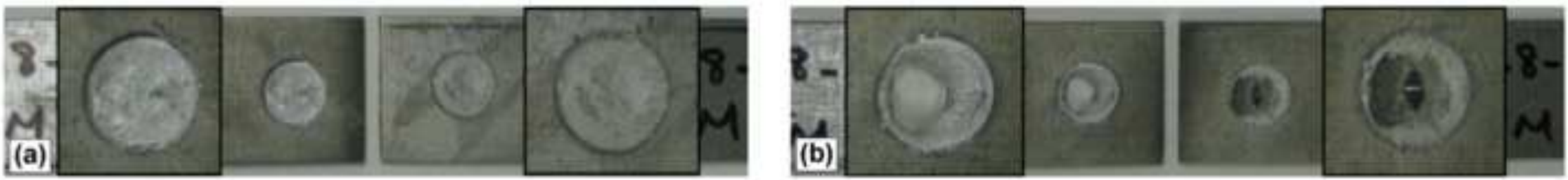

Figure 8 
Figure 9-Color (for Web only)
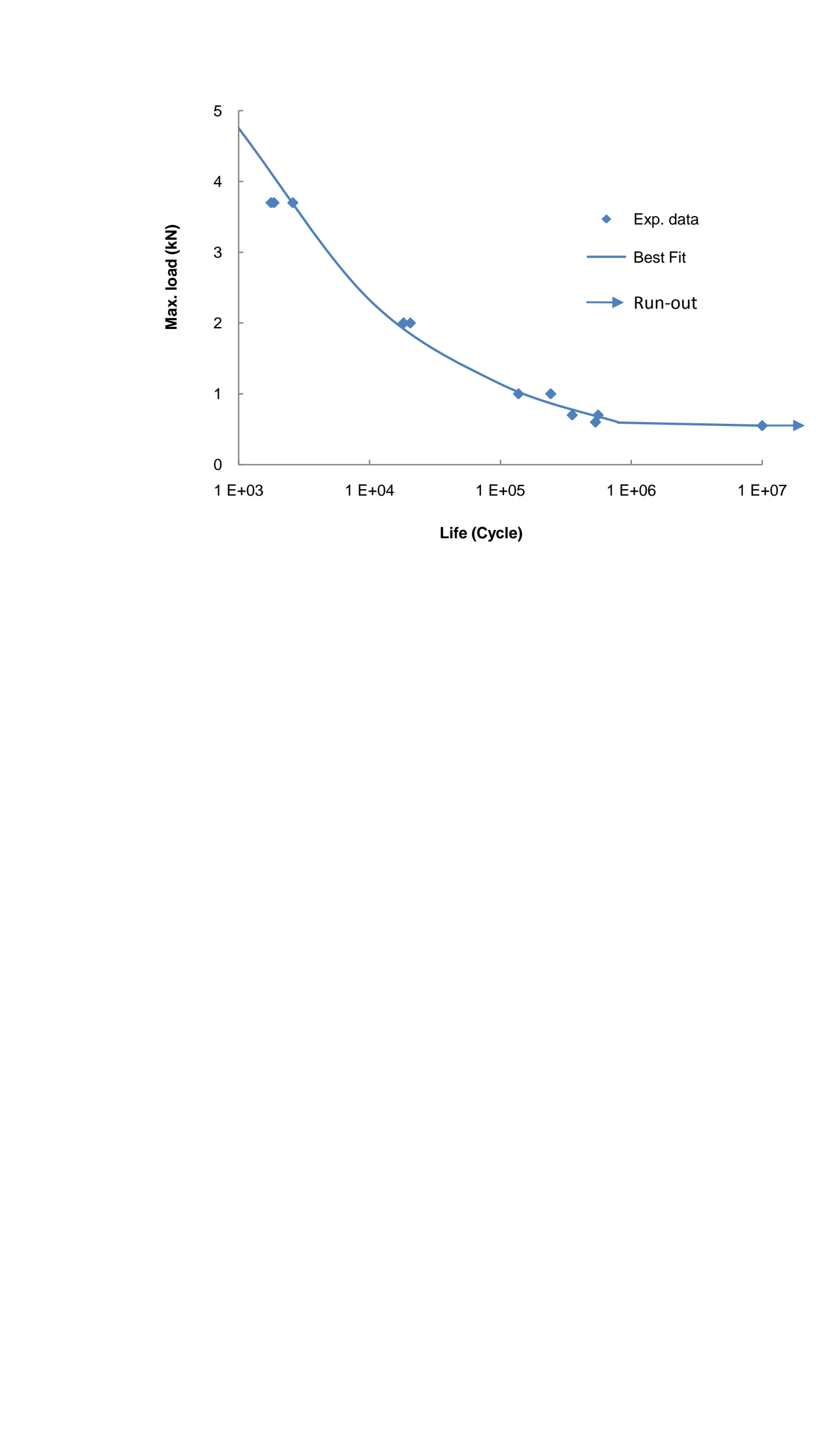

.

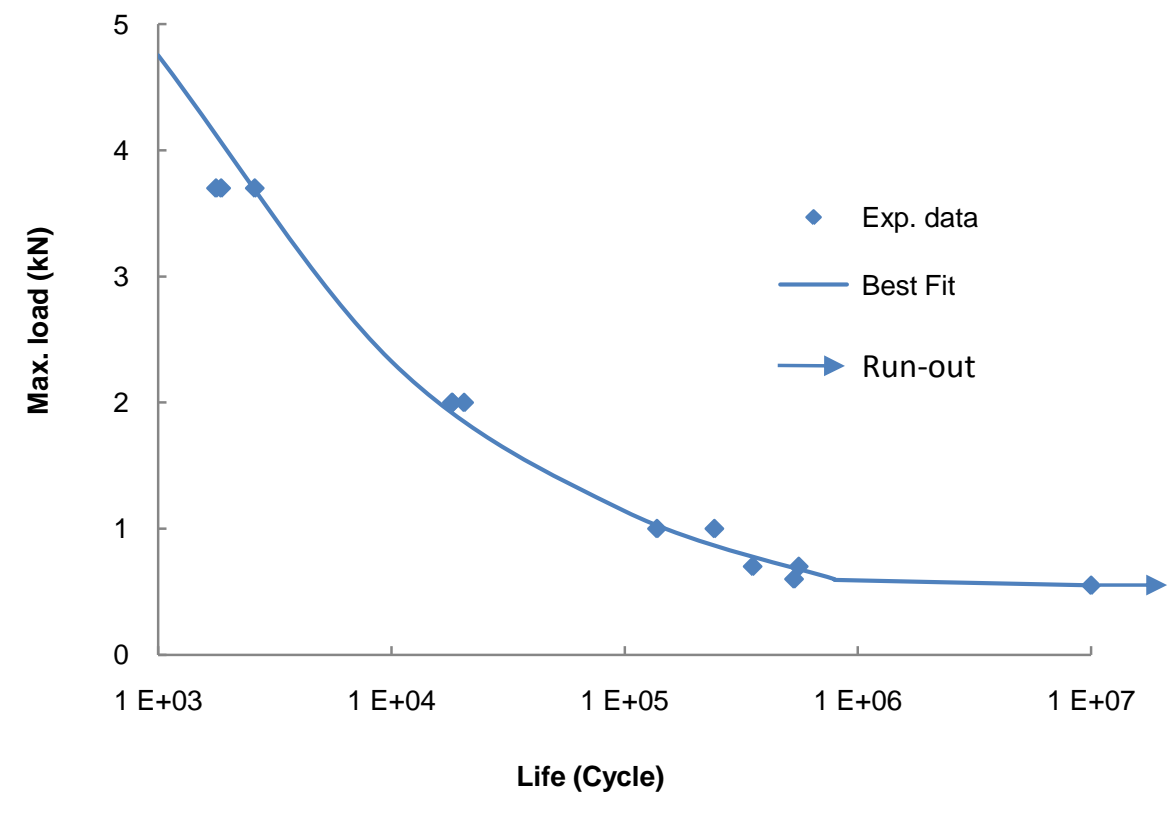


Click here to download high resolution image
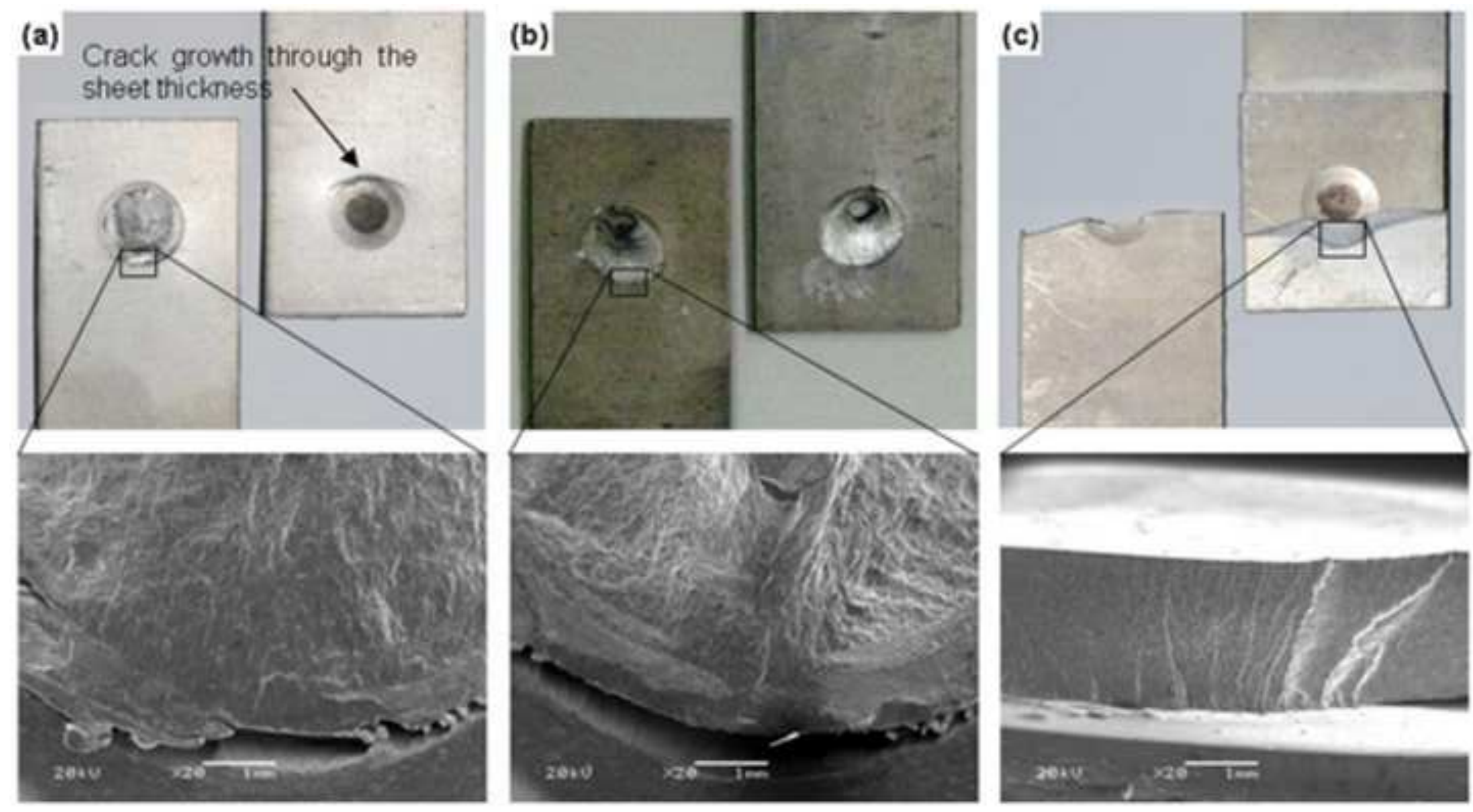
Click here to download high resolution image

(a) HCF -

(b) LCF $\rightarrow$
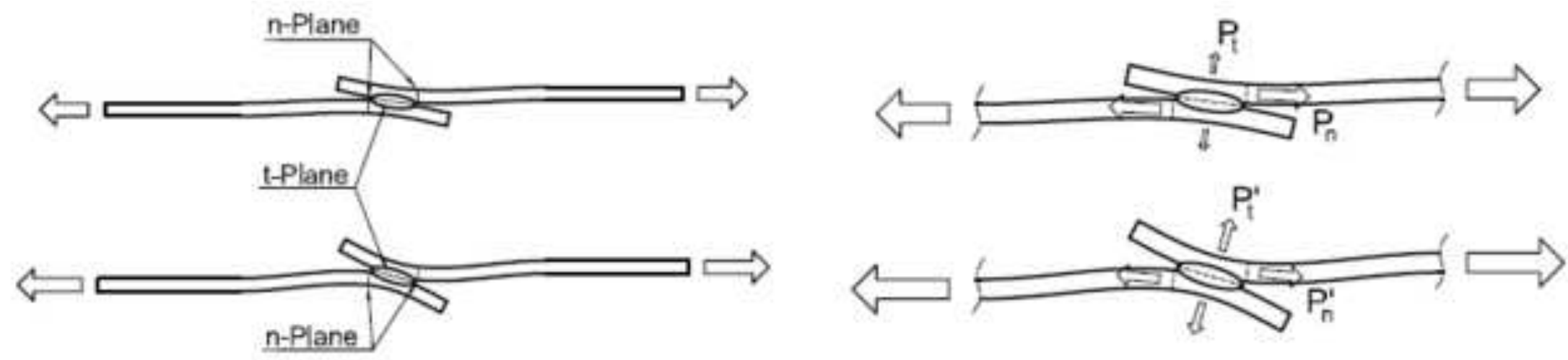


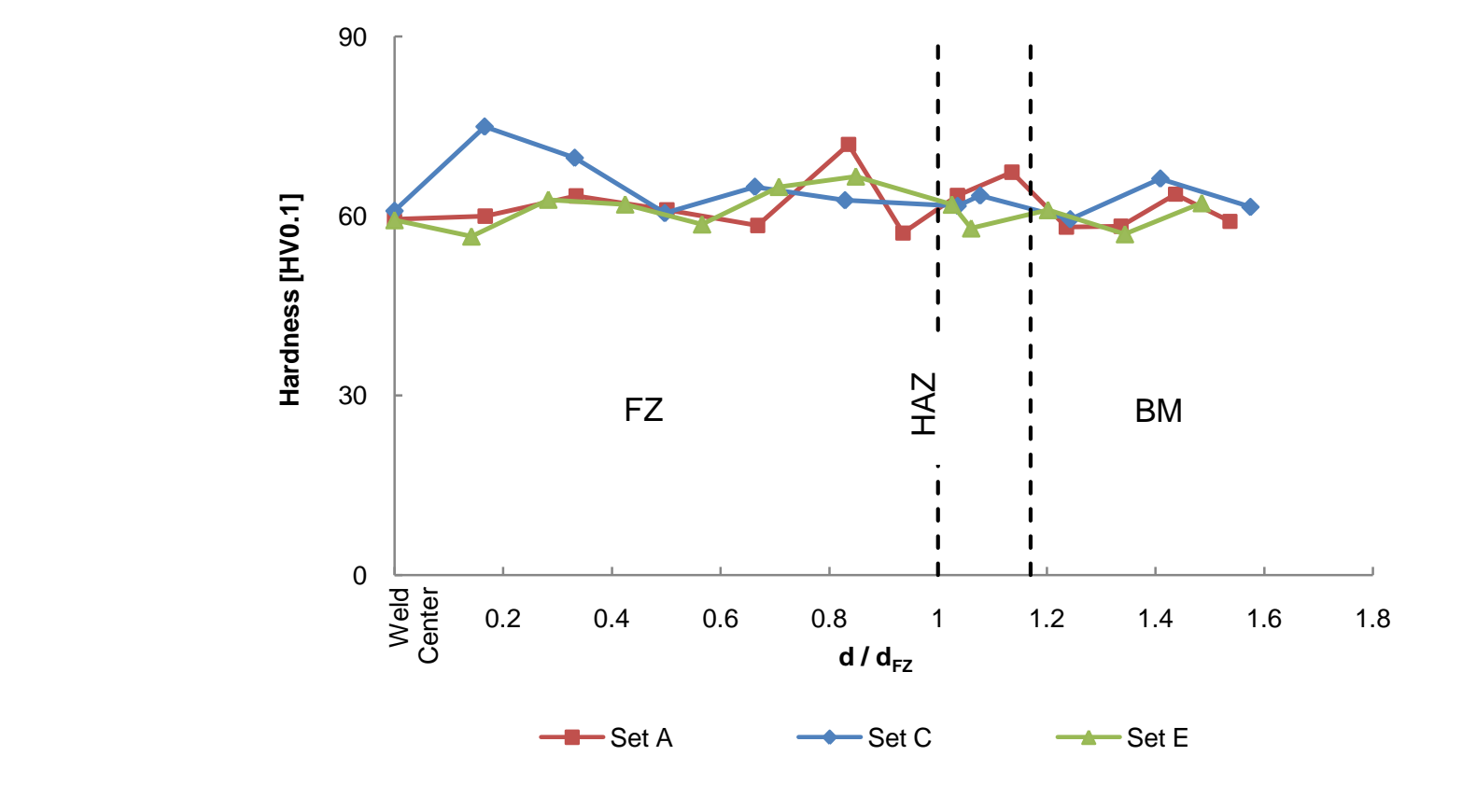

Figure 12-Color (for Web only)

Figure 12-Color (for Web only)

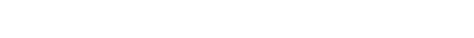

.

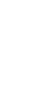

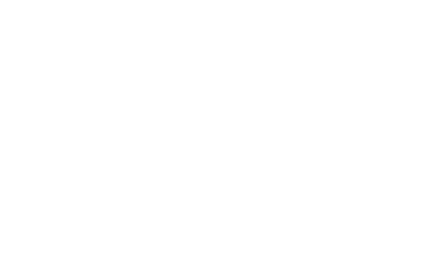

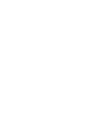

-


Figure 12-Grayscale (for print)

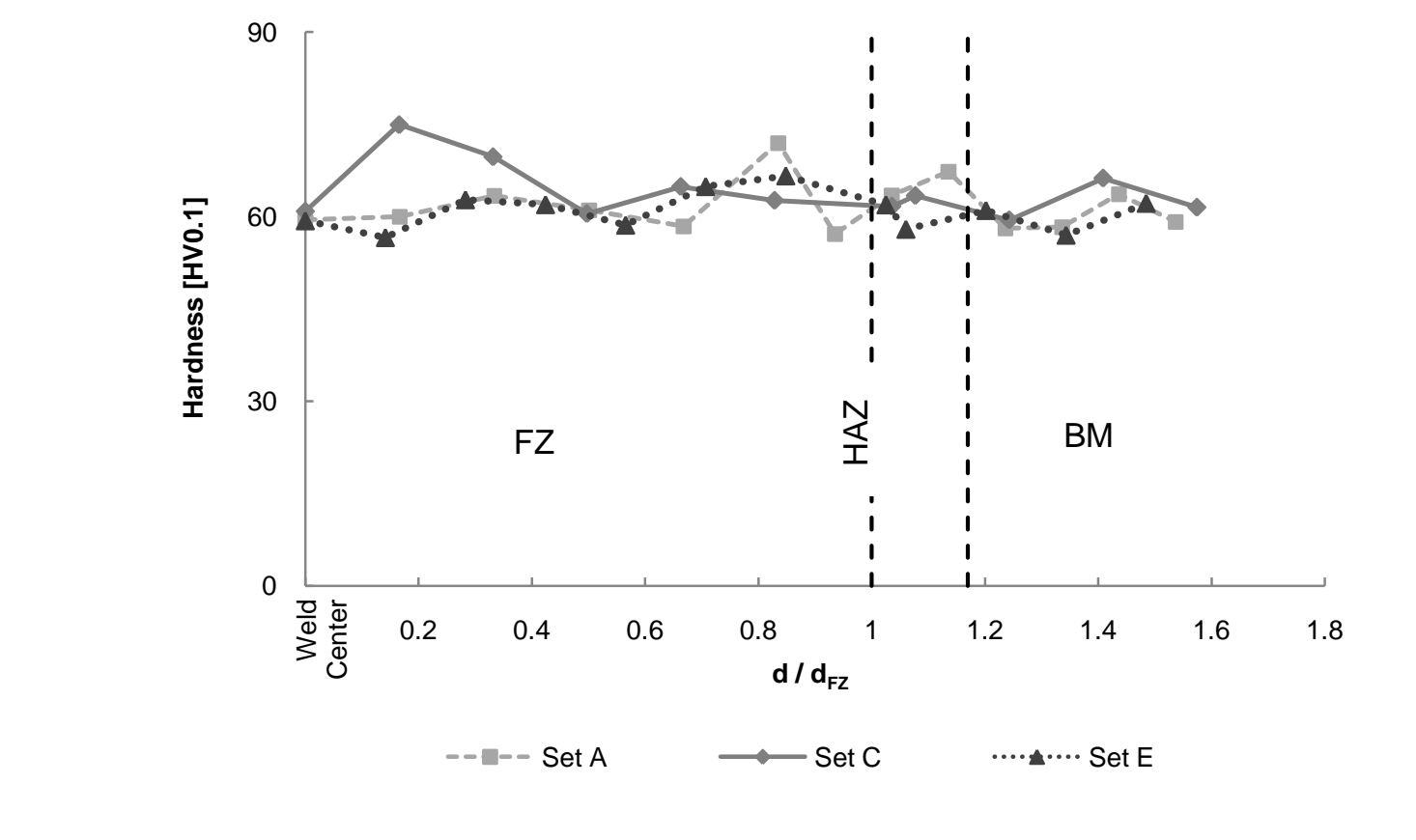

\section{igure 12-Grayscale (for print)}

$x^{2}$

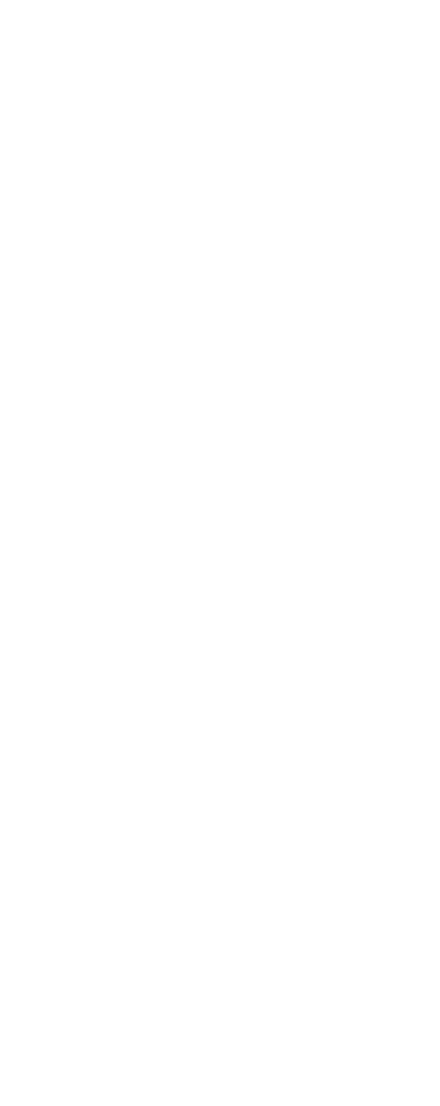

$+2$

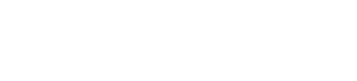

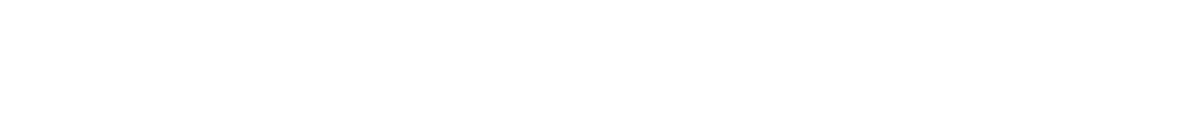




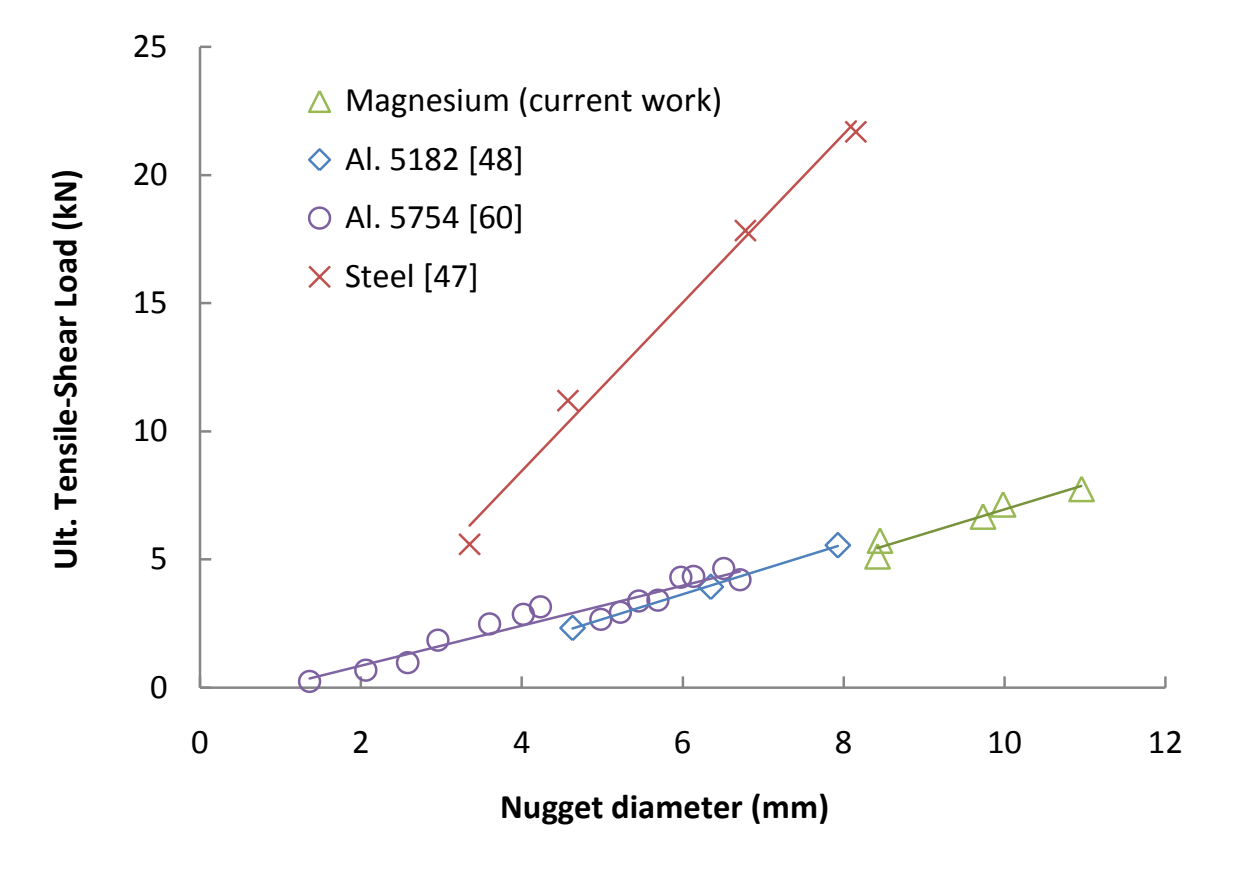

Figure 13-Color (for Web only)

2

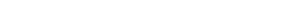

.

\section{.}




\section{Fure 15}

Click here to download high resolution image

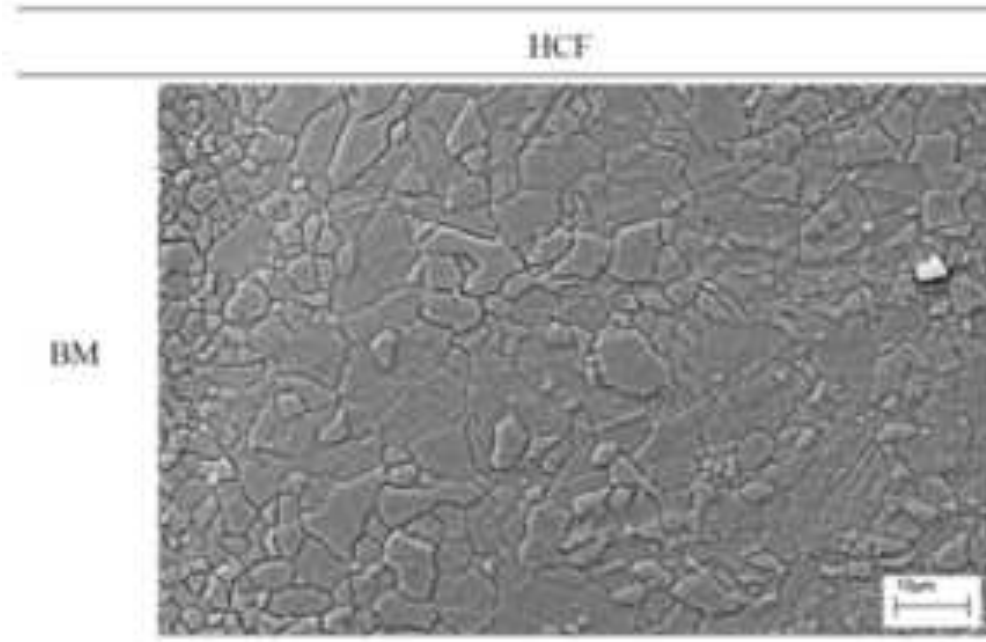

ICF
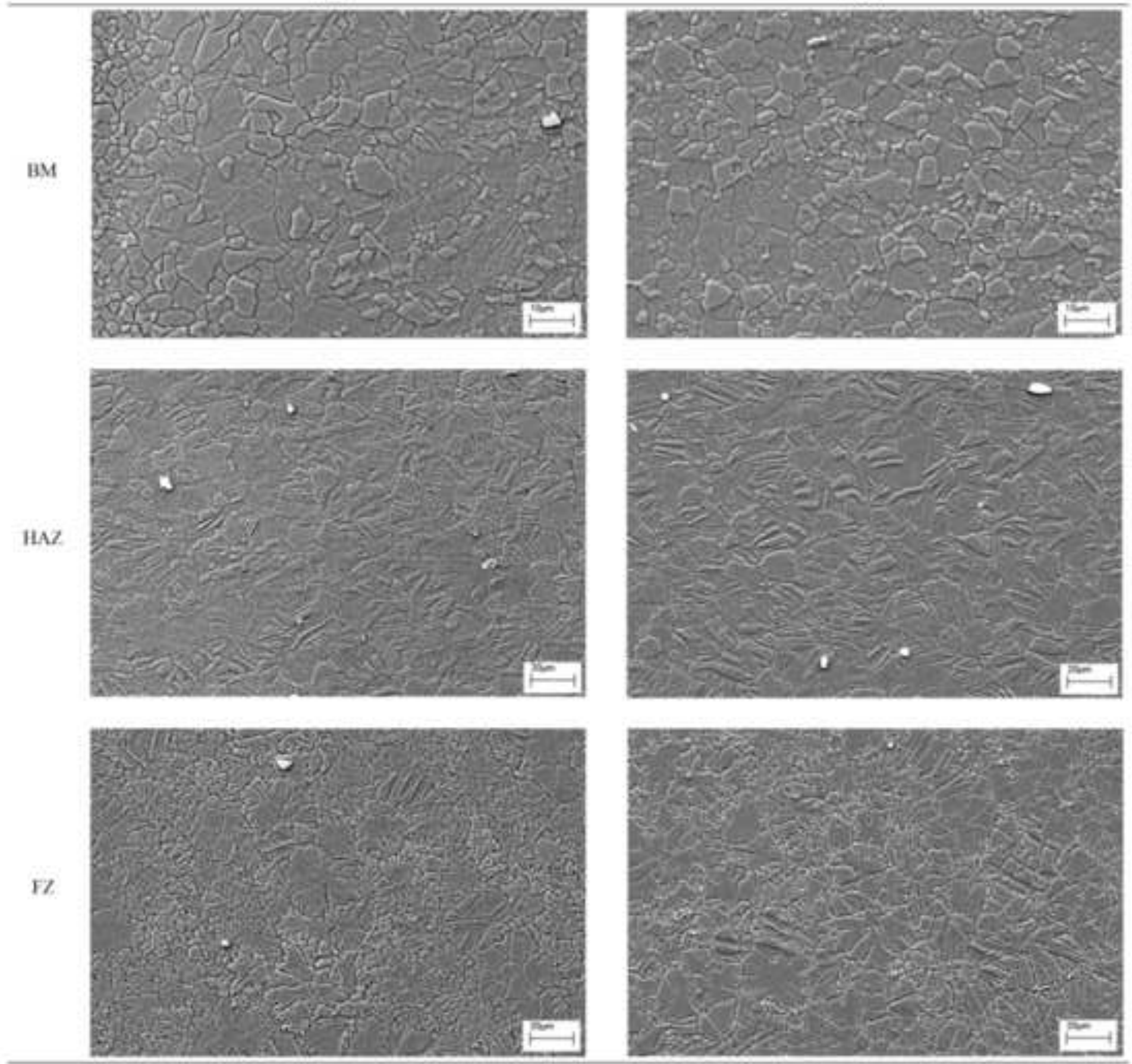


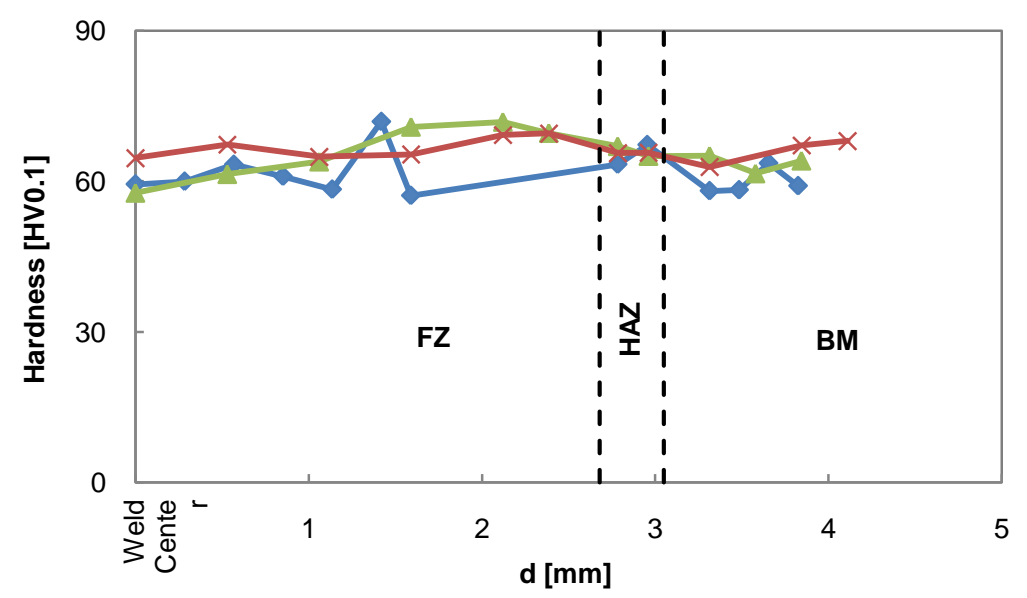

(a) $\rightarrow \mathrm{A}-\mathrm{BL} \quad \longrightarrow$ A-LCF $\rightarrow \mathrm{A}-\mathrm{HCF}$

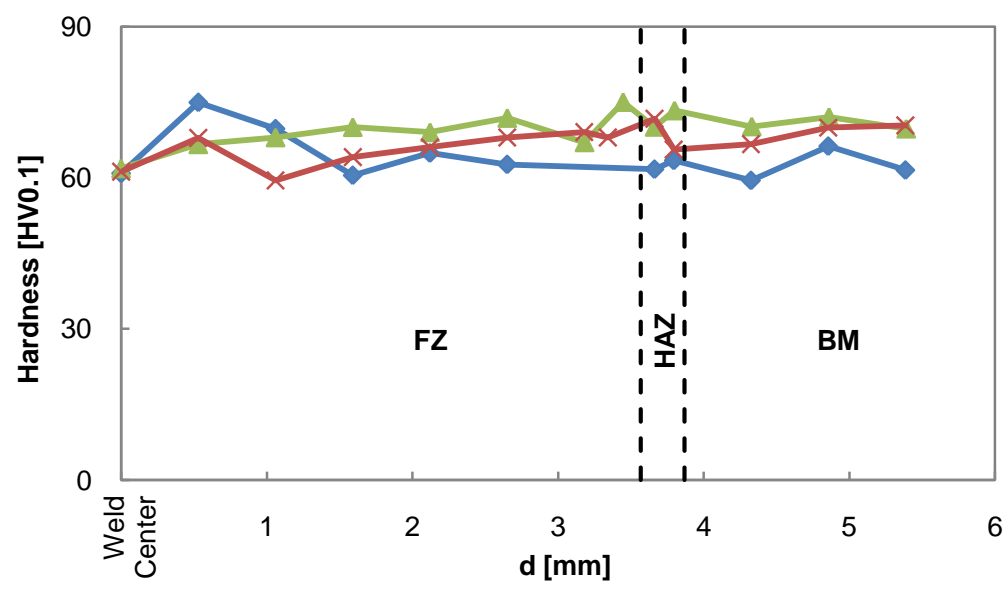

(b) $\because \mathrm{C}-\mathrm{BL} \quad \longleftarrow$ C-LCF $\quad *$ C-HCF

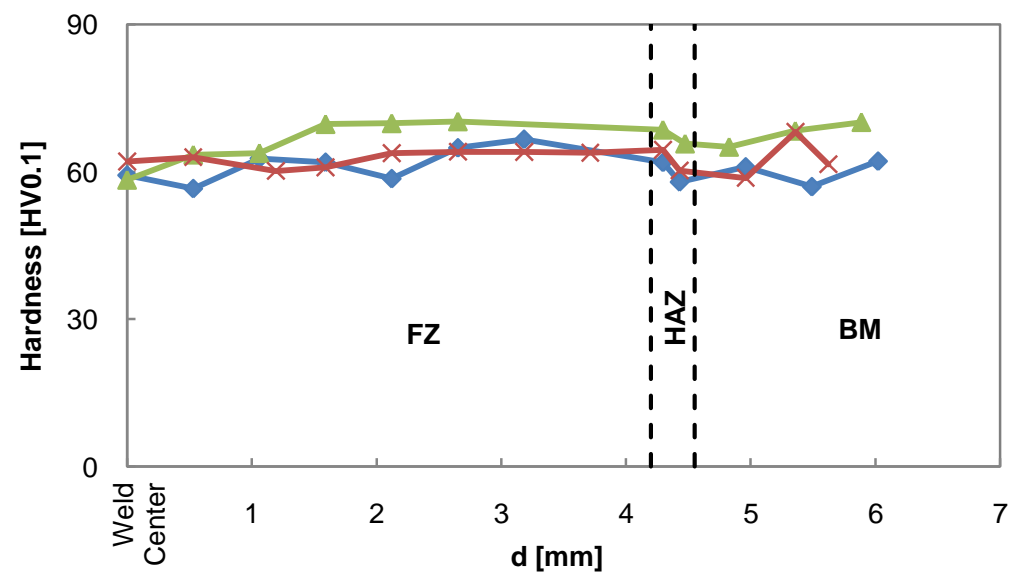

(c) $\longrightarrow$ E-BL $\quad \longrightarrow$ E-LCF $\quad$ E-HCF 


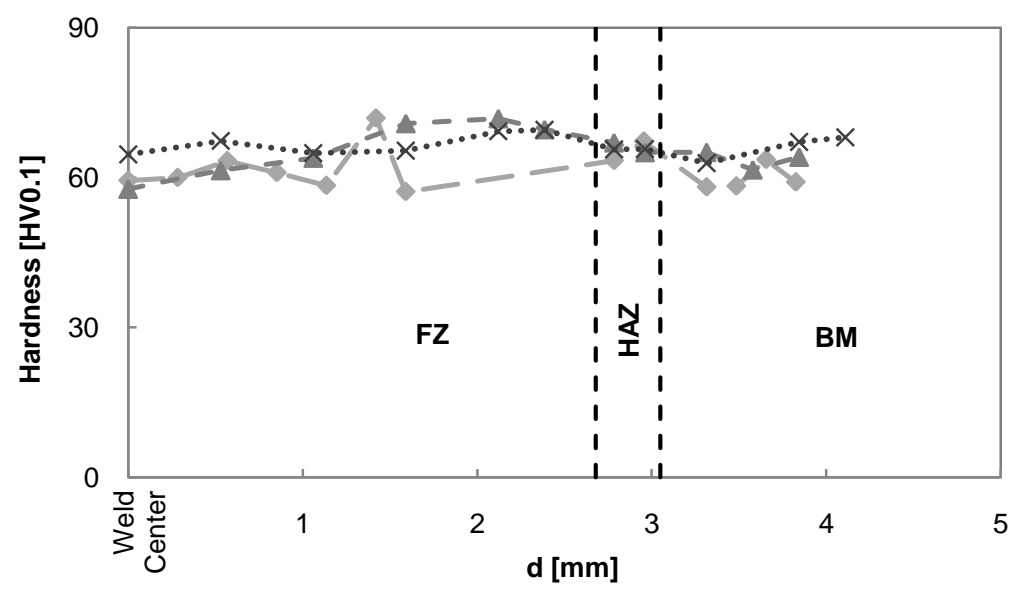

(a) $\longrightarrow \mathrm{A}-\mathrm{BL} \quad-\rightarrow-\mathrm{A}-\mathrm{LCF} \quad \cdots \times \times \cdot \cdots$ A-HCF

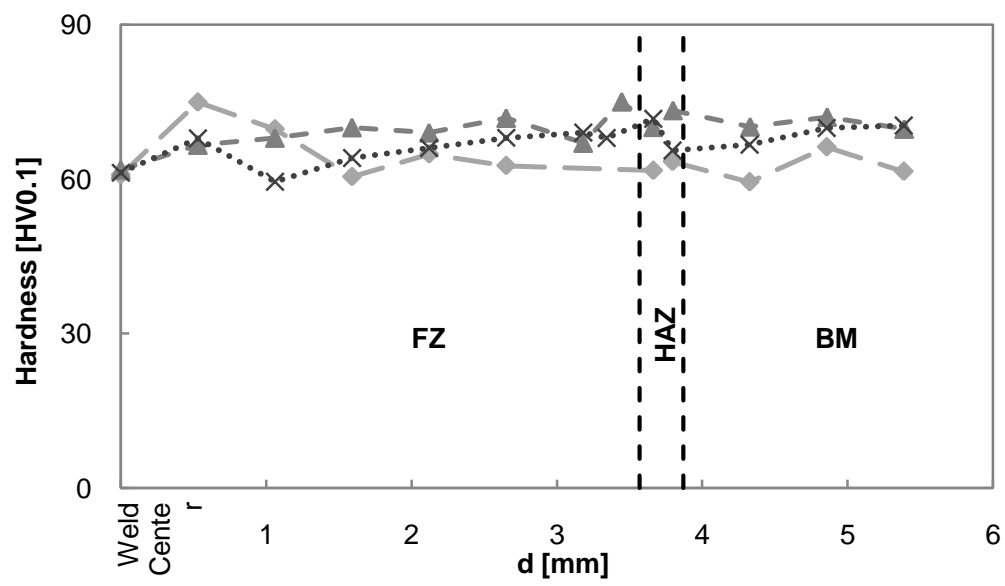

(b) $\quad \longrightarrow$ C-BL $\quad \pm-$ C-LCF $\cdots \cdots \times \cdots \cdot$ C-HCF

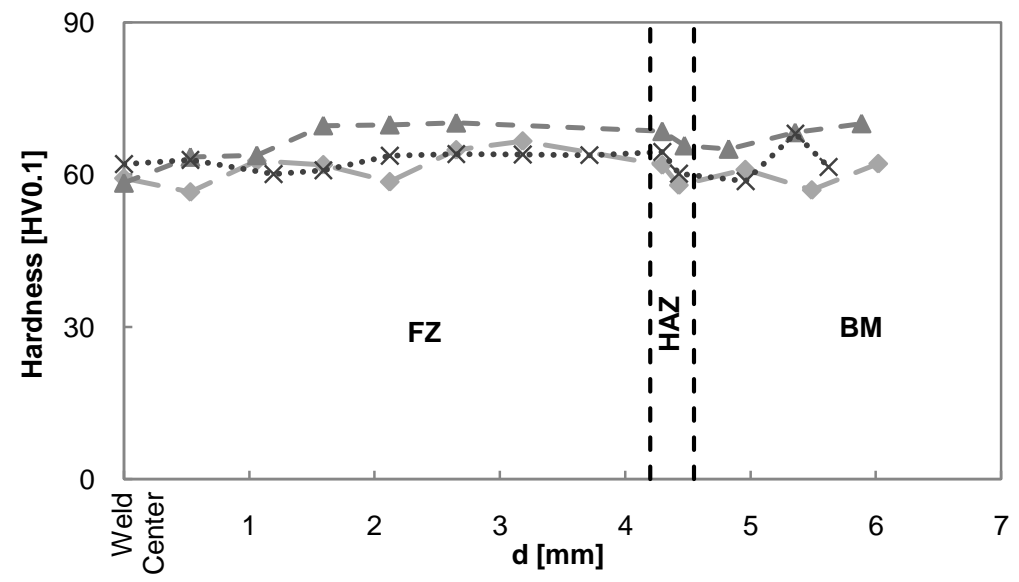

(c) $\longrightarrow$ E-BL $\quad \rightarrow-$ E-LCF $\cdots \cdot \times \cdots \cdot$ E-HCF 
Click here to download high resolution image
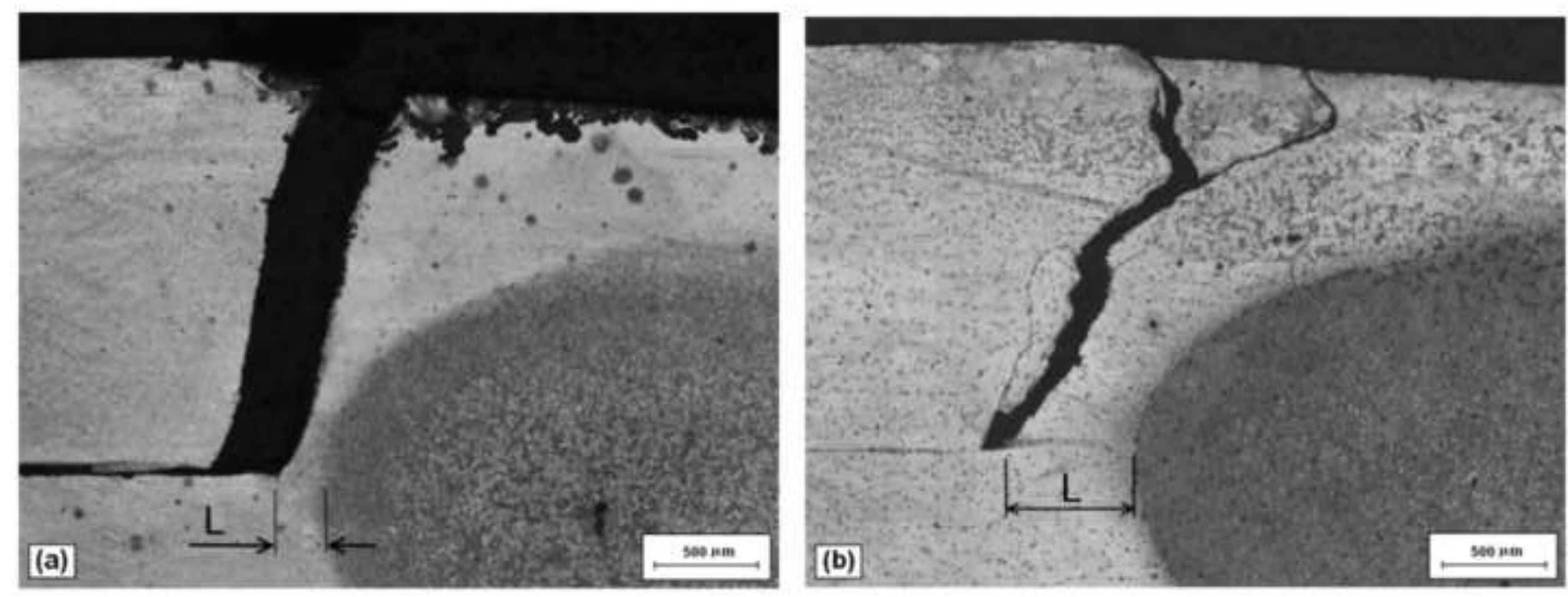

(b) 


\section{Figure 18-Color (for Web only)}

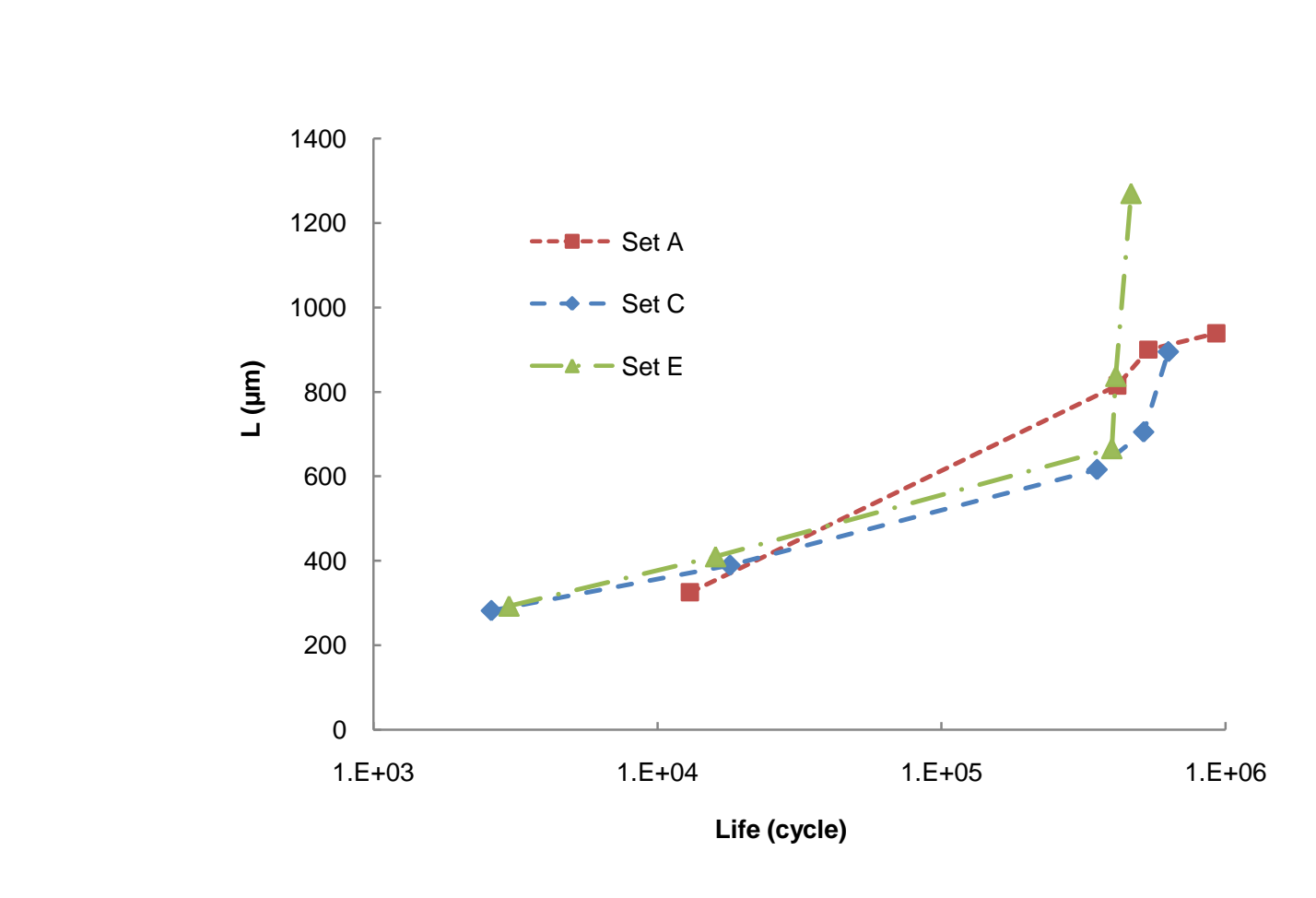

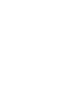

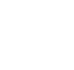

)

(n)

- n
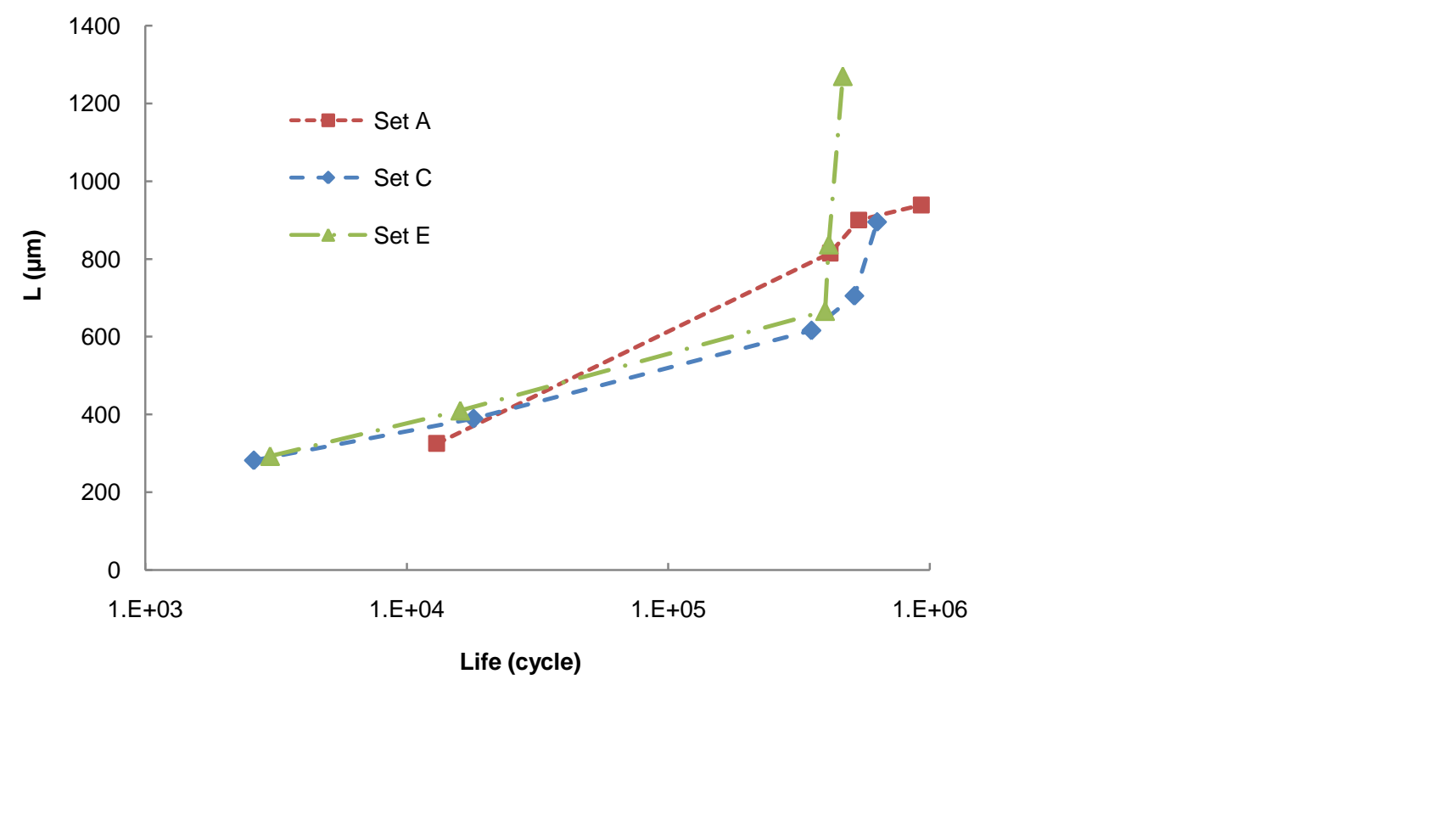
Figure 19
Click here to download high resolution image
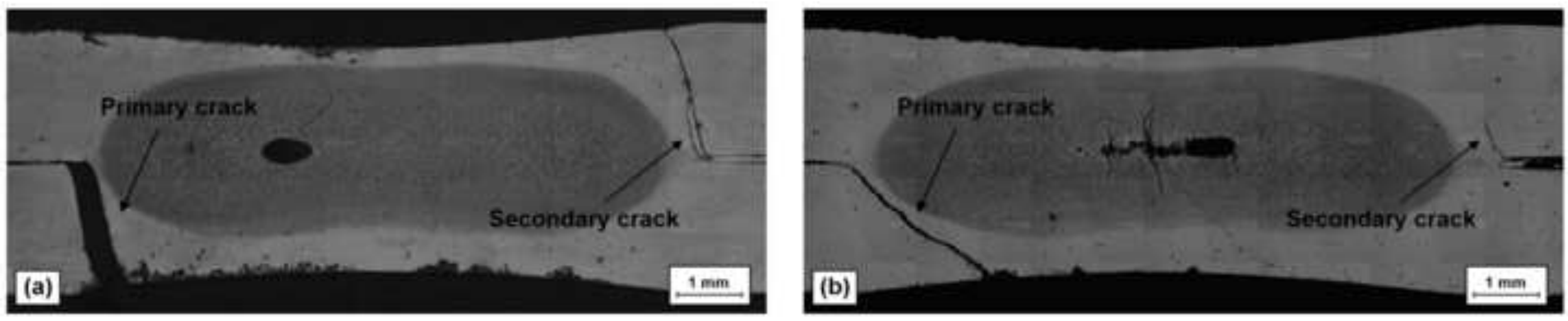
Click here to download high resolution image

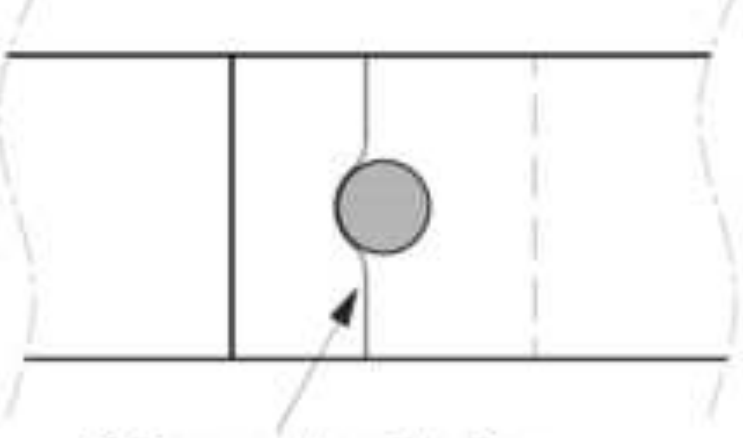

Primary crack on interface and sheet outer surface

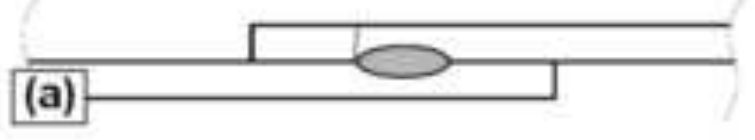

Primary crack on sheet outer surface

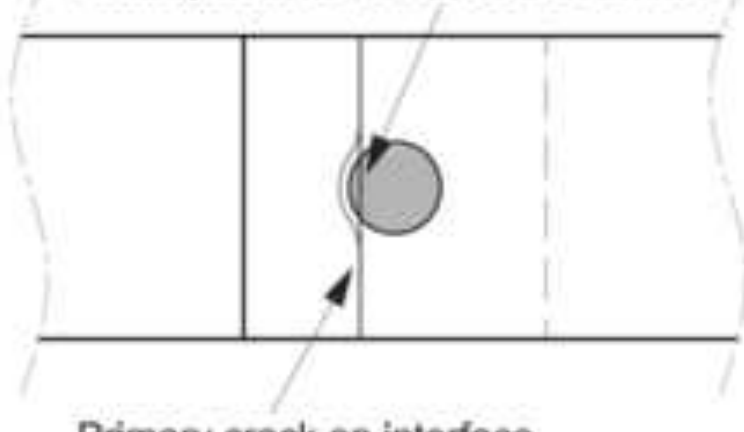

Primary crack on interface

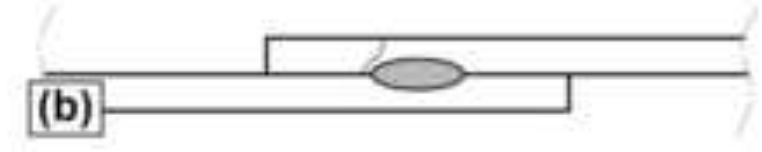

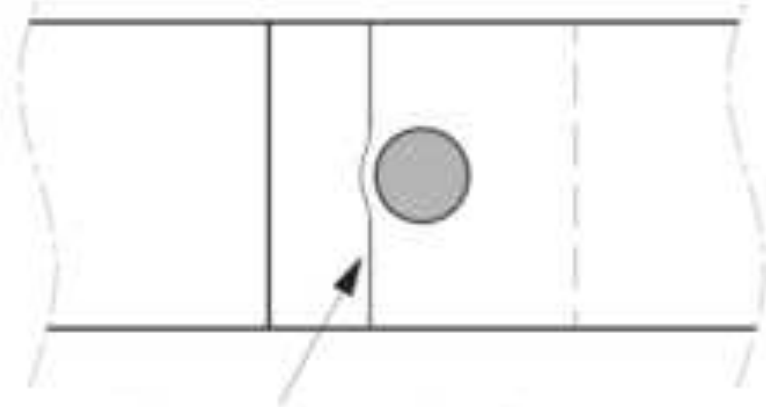

Primary crack on interface and sheet outer surface

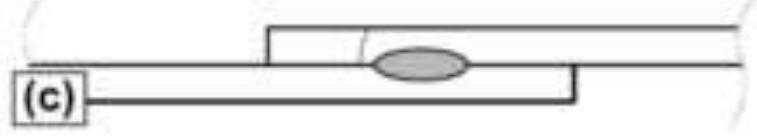

